Sciendo Journal of Polish Hyperbaric Medicine and Technology Society

Faculty of Mechanical and Electrical Engineering of the Polish Naval Academy

\title{
CONTEXT ANALYSIS IN THE DEVELOPMENT OF DIVING TECHNOLOGIES
}

\author{
Ryszard Kłos
}

Polish Naval Academy, Department of Underwater Work Technology in Gdynia, Poland

\section{ABSTRACT}

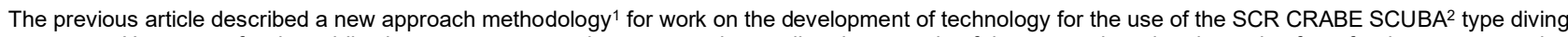
apparatus. However, after its publication numerous questions emerged regarding the genesis of the research undertaken, also from foreign partners using the same rebreather. The work on changing the technology of use was preceded by analyses, which were available only to people involved in the decisionmaking process. Demonstrating all the details of the decision-making process may be tedious, but failing to present them at all might raise justified doubts about the advisability of conducting a long-term research cycle.

This article only presents preliminary analyses. The necessity to perform them resulted from the specific requirements for military technologies ${ }^{3}$ which, as broadly as possible, should be knowledge-based. The knowledge-based approach by its very nature allows continuous improvement of the adequacy of the predictions made, the estimation of the level of risk when diagnosing deviations from the repeatability or precision of the model, and the possibility of adapting the technology to the changing requirements of the user resulting from tactical considerations of its use.

Keywords: Semi-Closed Circuit Rebreather, modelling the process of decompression.

ARTICLE INFO

PolHypRes 2019 Vol. 67 Issue 2 pp. 7 - 58

ISSN: 1734-7009 elSSN: 2084-0535

DOI: $10.2478 / \mathrm{phr}-2019-0005$

Original article

Pages: 52, figures: 1 , tables: 5

page www of the periodical: www.phr.net.pl

Submission date: 13.02.2019 r.

Publisher

Polish Hyperbaric Medicine and Technology Society 


\section{INTRODUCTION}

The methods of acquiring knowledge, differences in the analytical and holistic approach to problem solving and the process approach to developing technologies were outlined in the previous article [1]. These issues will not be repeated or further developed in this paper ${ }^{4}$.

\section{DIVING PROCESS OBJECTIVE}

In each project there should be defined assumptions concerning it's objective; propositions of the process used to achieve it 5 ; specification ${ }^{6}$ of the minimum and optimal structure for the proposed system that can ensure consistent, stable and effective implementation of the proposed process, taking into account the impact of the process on the environment and the impact of the environment on the system and the occurring process.

Initially, only processes in which the diver's body was exposed to pressure were considered as dives, while dives using single-atmospheric diving suits were considered as the use of an underwater vehicle. Now, due to the required training and the necessity to carry out tasks autonomously, the term diver is also extended to aquanauts using a single-atmospheric suit.

Different goals can be set for the diving process. Depending on the expected end goal of the diving process, an appropriate system should be established which is capable of ensuring the sustainability of the readiness to achieve the diving objectives. Different subdivisions can be applied according to the purpose of the diving process, for instance:

- $\quad$ extreme

- $\quad$ sports

- recreational

- technical

- professional

- rescue

- military

- etc.

The minimum system capable of ensuring the continuous maintenance of the diving process conducted for a specified purpose is merely a theoretical construction. System minimisation most often is applied in extreme dives, which are conducted in order to set a record. Under these conditions, the usual main assumption is to enhance the system with minimum security measures or ensure redundancy ${ }^{7}$ of some of the elements of the system ${ }^{8}$. The elements that go beyond the minimum structure of the system to achieve the objective of the diving process are the result of a risk analysis and feasibility study.

Illustratively, the minimisation of the diving system can be analysed using the example of dives performed by sponge divers described in historical travel books.

The minimum system needed to carry out the diving process consists of only a trained diver. The element of the diving training system can be divided into two subsystems: swimming lessons and training in diving whilst holding one's breath. However, the feasibility study shows that a trained diver will work more effectively if he is equipped with a sponge cutter which, according to the risk analysis, can also be used to assist in the protection of the diver. If a diver is well-trained and can withstand a longer period of time with his breath held, then the effectiveness analysis for the diving process in order to harvest sponges shows that he should be additionally equipped with a net for collecting sponges.

The feasibility study shows that sponges are unlikely to grow close to the shore and that the effectiveness of swimming far from the shore is unlikely to be acceptable, thus it is necessary to ensure that the diver is able to travel by boat. When focusing only on the diving system, the boat should be considered as an element of the system environment, i.e. the context surrounding the diving system under consideration. It should be noted that in this context, there are also other elements that affect the diving system for sponge harvesting, which should be taken into account in the feasibility study, such as market demand or the threat of a shark attack.

Subsequent risk analyses, technical feasibility or economic viability studies may relate to the use of an air pump or air compressor, an air supply system with or without filtration, the use of an air supply regulator, the use of a mask, fins, access to health care, social security or pension systems. Defining the objective to be achieved by an established process can thus be used to establish the structure of the system that supports it, taking into account the environmental impact on the system and the impact of the system on the environment.

For the division proposed here, the distinguishing feature of these types of dives is precisely the definition of their different objectives. Extreme dives are usually carried out in order to break records, but they can be a part of a rescue operation or a quickly changing tactical scenario for a combat situation. Typical examples of extreme divers include free diving where a breath holding diver is dragged to an extreme depth riding on a weighted sledge, or alternatively where the diver reaches the desired depth under his/her own effort using fins (either after being initially pushed to a certain depth by the second diver or reaching it by his/her self). Sport dives, in turn, are carried out for competitive purposes. For example, underwater spear fishing championships previously consisted of catching fish in a defined time, though nowadays photographic competitions are more common. Recreational dives are carried out for pleasure. Technical diving originated from the desire to explore greater depths, and for a greater durations than had previously been possible, the achievement of this goal requiring the use of special, complicated equipment. Technical dives are often implemented, as well as extreme dives, to break records of depth, time spent underwater, or exploring some areas, such as wrecks or caves. Professional diving involves the use of a variety of technical equipment for conducting commercial underwater activities. A specific type of professional diving involves operations to save lives. The rescue of property is part of typical commercial professional diving. Life-saving dives are characterised by different dynamics and determination from other types of diving. Moreover, they use other procedures and carry additional equipment for the victims. Technical dives have emerged from military dives, but their purpose is non-military. The objectives of military dives may vary, for example in combat dives the objectives are usually different from MCM dives ${ }^{9}$.

According to the aim of the diving process, different approaches are used to build a system ensuring that the process runs smoothly, efficiently and safely. 
During underwater works, both divers and diving supervisors prefer to carry out decompression according to low-risk regimes ${ }^{10}$, therefore a conservatism function has been introduced into decompression programmes, using e.g. the method of calculation for elevated inert gas content compared to actual, assuming an increased depth compared to the actual depth, assuming longer than actual time at depth, or using an asymmetric model for saturation/desaturation of theoretical tissues ${ }^{11}$. Some programmes use more than one of these methods or a combination of them to increase decompression safety. These methods are called conservative methodologies or are referred to simply as conservatism ${ }^{12}$. Conservatism is often specified by indicating how much longer and deeper the decompression profile should be compared to the actual one. Sometimes you can find a numerical expression for conservatism, e.g.: in percentages related to the saturation gradient 13 . Diving technologies may be categorised according to their level of conservatism.

In the case of extreme dives, the technology of diving is chosen individually for the diver. Most often the concept of conservatism for this type of dives does not occur, as the typical practice is to exceed the typical safety limits to which conservatism refers. The occurrence of a diving accident is considered to be part of extreme diving and the security measures are related to the development of treatment systems as close as possible to the place where extreme diving is organised. In technical diving, technology is often dedicated to the task and the current advancement of the divers' training. Often technology, and especially decompression schedules, are selected for the current course of diving by computer systems supporting the process of diving, taking into account changes not only in depth and time of stay, but also variations in temperature, gas consumption or changes in conservatism settings. Technical dives do not cross the threshold of zero conservatism, as is the case with extreme dives. A proportion of technical diving is scientific diving conducted in order to get to know the water environment, both animate and inanimate. Due to the fact that the diving is performed by scientists, also advanced in age, conservatism is selected for them individually at an elevated level.

In sports diving, the level of conservatism exceeds the typical conservatism level of $30 \%$, which is the limit for diving with safe, albeit strenuous, decompression. It is consensually agreed and is identical for all diving participants. The differences lie in the way of preparing for the sports diving process, which constitutes a hidden handicap of individual competitors.

In the case of recreational diving, the level of conservatism is selected in such a way that the risk of diving-related illnesses DCI ${ }^{14}$ be lower than $1 \%$ in accordance with the estimation as for the epidemiological threat for the entire population admitted to diving by checking compliance with medical standards [2]. Part of recreational diving is rehabilitation diving, less frequently practiced in the form of medical rehabilitation 15 , and more commonly in the form of social rehabilitation ${ }^{16}$.

In professional diving, medical standards are usually more elaborate and rigorous than in recreational diving. Conservatism is often set at the same level as for recreational diving, but no longer applies to the entire population that can dive, but to a selected population that meets higher requirements than the average individual in the professional diving population. If, for professional dives, the risk of DCI is higher than $1 \%$ in the estimation as for an epidemiological risk, for a selected population meeting the special requirements set in medical standards, similarly as in normal procedures of work protection, divers must give informed consent to derogations and the risk incurred should be compensated both in terms of health protection and financial compensation.

Rescue dives are characterised not only by an increase in the risk of an occurrence of the DCI symptoms, but also by the risk of a technical accident due to the failure of the equipment used ${ }^{17}$. Increasing the risk of DCI is only allowed when directly saving lives ${ }^{18}$ Hence, most often in rescue operations conservatism is maintained at the level typical for professional diving. This applies of course to the group of strictly selected and trained divers secured by specialists in various fields, needed in the rescue operation.

Military dives are characterised by different levels of risk of DCI. For EOD dives ${ }^{19}$ the same rules apply as for rescue dives. For MCM dives, depending on the importance of the mission, it is possible to approve the threat of the occurrence of DCI symptoms from the level of EOD dives to combat missions SRT ${ }^{20}$, for which the typical DCI threat is determined at the level 21 of $5 \%$ in terms of estimation, as for the epidemiological threat, for a selected population meeting the special requirements set out in medical standards ${ }^{22}$.

This shows that military diving technologies should be based as broadly as possible on knowledge. Other technologies can be bought. Even with technical dives, broader but available knowledge is sufficient to make decisions about the risks to be taken, which is enabled by the algorithm embedded in the computer memory to support decision-making about the decompression process used.

The project concerns the MCM diving technology with the use of an independent diving apparatus with a semi-closed circuit of the breathing mix - SCR CRABE SCUBA, carried out in a wide range of depths, as an element of the mine warfare system. Dives should be conducted from the surface to a depth of about $80 \mathrm{mH} 20$ and to cover different depth ranges oxygen for decompression and various nitro-oxygen mixtures will be used, to a depth ${ }^{23}$ of $50 \mathrm{mH}_{2} \mathrm{O}$, whereas at a deeper level helium-based 24 mixtures will be used. The context of the use of diving technologies as elements of the mine warfare system seems to be particularly important. The aim should be to make the technology's conservatism as effective as possible and to create a risk within the limits of $25(1 ; 3) \%$ in terms of its estimation, as for an epidemiological threat, for a selected population meeting the special requirements set out in medical standards.

\section{Physiological Context}

The basic requirements for conducting diving operations using self-contained diving devices result from the risk of decompression sickness DCS 26 and central oxygen toxicity ${ }^{27}$ CNSyn.

Among the basic decompression parameters, the following assumptions for exposure can be distinguished:

- maximum planned depth of hyperbaric exposure,

- exposure time at maximum depth,

- breathing mix used,

- diver's predisposition to undergo a hyperbaric exposure. 
Usually, the depth $\mathrm{H}$ is a complicated functional dependence on the time of exposure $t: H=f(t) . H=f(t)$ can be approximated by a pair of parameters: maximum depth of exposure $\mathrm{H}_{\max }$ and time of stay at maximum depth $t\left(\mathrm{H}_{\max }\right)$. An extremely important parameter for planning effective, safe exposure and decompression is the oxygen partial pressure $p_{i}$, which is typically a function of the exposure and decompression times $t: p_{i}=f(t)$. During descent and stay at the bottom, it is most common to use a single operational mixture to supply the diving apparatus, but depending on its design, it can maintain the partial pressure of oxygen $p_{i}$ within very narrow or very wide ranges.

Planning to perform long-term intensive work in diving operations outside the saturation zone is troublesome due to the lack of possibility to design adequate decompression [3]. Strenuous work induces the need for an adequate response from the diver's body. Most often, the response is to include anaerobic changes causing the formation of lactic acid in the muscles, which by acidifying the blood causes a decrease in the efficiency of oxygen transportation through haemoglobin [4].

These effects differ in individuals $\theta$ and for one and the same individual strongly depend on the current training $\theta_{\mathrm{i}}=\mathrm{f}(\mathrm{t})$, preparation ${ }^{28}$ or even attitude to diving. It is difficult to take some individual parameters into account when planning adequate decompression for the population. During saturated dives time is given for stabilisation prior to the decompression process. This time depends on the type of work performed earlier and can amount to up to 2 days.

As mentioned above, with a simplified approach to the decompression planning process, two parameters are used: the maximum depth of exposure reached $\mathrm{H}_{\max }$ and the exposure time at maximum depth $t\left(\mathrm{H}_{\max }\right)$, calculated from the beginning of the immersion to the initiation of the decompression process. The maximum exposure depth $\mathrm{H}_{\max }$ may be reached just for a moment 29 with the decompression process starting from the moment when the pressure can only decrease; except for the required stops at decompression stations. If the stops at the decompression stations become longer, the decompression schedule may also change. This way of planning the decompression process is based on the worst case scenario selection procedure. This increases the conservatism of the adopted decompression procedure in a variable way, depending on the diving conditions and the diving supervisor's approach to decompression planning. It should be noted that an unjustified increase in conservatism may result in inefficiency in the diving process due to the significant oversizing of the decompression process. In accordance with the tradition of the Polish Navy, the project was based on the selection of the decompression process using the worst-case scenario method.

The decompression and compression processes may also occur at constant pressure when the composition of the breathing mix changes [3]. Isobaric decompression processes are accompanied by oxygen decompression. Replacement of the gas mixture with pure oxygen results in the washing out of inert gases by oxygen from the tissues. Oxygen is removed from the body, mainly through metabolic consumption. Isobaric decompression occurs at oxygen decompression stations. Due to its toxicity, oxygen can only be used at relatively shallow decompression stations. It is accepted around the world that oxygen decompression can be started from a depth of $12 \mathrm{mH} 20$.
The Polish Navy has a long tradition of using oxygen decompression starting from $15 \mathrm{mH} 20$, but in order to maintain interoperability in diving with SCR CRABE SCUBA, oxygen decompression was planned from 12 $\mathrm{mH} 2 \mathrm{O}$, however, the breathing space of the diving apparatus will be ventilated with oxygen as early as 15 mH2O. Decompression can also be accelerated by using oxygen-enriched gas mixtures. The mechanism is similar and the use of such mixtures can begin before the transition to oxygen decompression. However, it is possible to use a mixture other than one enriched with oxygen. For example, by substituting Trimix with Nitrox ${ }^{30}$ In such a case, even at constant external pressure, Nitrox will elute helium from tissues and replace it with nitrogen, i.e. the replacement of the breathing mix will cause the phenomena of isobaric decompression. It should be noted, however, that nitrogen is much better soluble in tissues containing fat than helium, so planning a long period of isobaric decompression if the breathing mix is changed from Trimix to Nitrox may prolong the decompression process instead of accelerating it. If this is not taken into account, symptoms of decompression sickness DCS may occur. Such a mechanism of the decompression sickness is known as DCS induced by the counter-diffusion process [5-7].

The diver's predisposition to hyperbaric exposure constitutes a complex of issues that may include:

- physical build,

- physical and mental state prior to diving,

- mental build,

- the current state of training,

- the scope of the hygiene rules applied, etc. In the past, diver's physical build was a basic parameter allowing him/her to perform military service as a diver or to work as a professional diver. This was related to the types of diving suits. Too tall a diver did not fit in a suit, while for a short diver a reefed suit posed a threat. For example, a crack in the crotch belt in a classic suit caused the escape of the helmet and the inability to release air from the suit leading to a diver being thrown up to the surface or hanging in the depths on a diving hose jammed with underwater obstacles. These days of course it is possible to produce a suit adapted to the diver. In the past, a strong body build was required for a classic diver, because the equipment worn on the surface weighed just under $100 \mathrm{~kg}$ and required sufficient physical strength to put it on and enter the water. Nowadays, the equipment and devices for professional divers are much lighter, but still require considerable physical strength to put them on and move around outside the aquatic environment ${ }^{31}$. Also, performing underwater works, although carried out with the use of tools and various types of equipment, often requires considerable physical effort, so that some works have to be performed only under saturation conditions.

The use of semi-closed-circuit breathing apparatus requires certain predispositions. The physiological parameters $\mathrm{HF}^{32}$ which influence the level of diving safety, are indicated here with the symbol $\theta$. For SCR CRABE SCUBA this is primarily the breathing module ${ }^{33} \varepsilon$.

The causes of certain phenomena34, are not always known and should therefore be the starting point for further scientific research. It is commonly believed that older divers require more conservative decompression procedures, but quite a large percentage of divers over 45 years of age exhibit a significant increase in individual immunity to strenuous decompression. This phenomenon 
was observed during monitoring of the formation of the free gaseous phase in veins during experimental dives, although earlier cases of individual immunity to difficult decompression had been noted 35 .

This phenomenon does not occur only as an individual property $\theta_{i}$, but it can change with the current psychophysical state ${ }^{36}$ of the diver. The influence of attitude or determination is not only observed when diving. There are many reliable attitude-related events, such as the occurrence of the phenomenon of imaginary pregnancy in humans and animals. It is believed that the diver is built up in $80 \%$ of his/her mental structure, especially the ability to operate effectively in stress and resistance to panic ${ }^{37}$. There is also a conviction that attitude is correlated with immunity to central oxygen toxicity CNSyn. It was also attempted to promote the view that deep knowledge-based consciousness is a contribution to facilitating the development of anxiety leading to panic in stressful situations. Indeed, it is observed that less educated divers show greater resistance, but once the fear barrier is broken, the development of stressful situations leading to the emergence of panic is extremely violent.

Experienced dive supervisors try to gain the trust of divers to become their trustees, which makes it easier for them to assess the current psychophysical condition of the diver. When assessing this state, it is important not to underestimate any symptoms, not even minor ones. It is good practice for the supervisor to have eye contact with the diver 38 during the preparation for diving, with simultaneous examination of the state of muscle tension, body tremor ${ }^{39}$ or evaluation of the heart rate ${ }^{40}$ etc. It is important to check the coordination of movement once the equipment is put on ${ }^{41}$.

It is important to detect signs of fatigue, early signs of illness, stress, etc., as they have a direct effect on the safety of decompression.

When repeating a dive, it is important to note the saturation of tissue with inert gases ${ }^{42}$ remaining after the previous decompression. Lowering the pressure value, as is the case during flights by airplanes or transport helicopters, may cause a serious imbalance in the pressure of gas in tissues resulting in the occurrence of symptoms of decompression sickness (DCS). The project did not include any studies on the possibility of cyclic dives ${ }^{43}$, repeated 44 dives or achieving a state of gas balance between tissues and breathing atmosphere ${ }^{45}$ on the surface ${ }^{46}$, but during the progress of works such studies may be conducted.

In addition to strength training, ensuring good physical fitness, and flexibility training, ensuring good muscle stretching 47 , it is also important to carry out adaptive training. Adaptive training is aimed at preparing the diver for hyperbaric conditions and decompression. Accustoming the body by clearing the path of gas exchange between tissues and respiratory atmosphere contributes to the safety of diving. In the design of the project it will be important to define the scope of such training and guidelines for strength or flexibility training.

Hygiene of life and work of a diver is a broad concept, as are the aforementioned complications resulting from making strenuous effort prior to diving. An important element is to undergo scheduled strength, endurance, stretching or adaptive training. One of the important elements is the aforementioned care for proper rest and anti-stress training. During training, a wellbalanced diet is crucial, limiting the possibility of accumulation of adipose tissue, but ensuring an adequate energy load. It is important to provide appropriate micronutrients and vitamins in their natural form rather than in the form of dietary supplements. Dietary supplements or medicines may cause the presence of condensation nuclei in the blood and thus increase susceptibility to easier formation of the free gaseous phase during decompression. However, solutions to this problem will not constitute partial objectives of the project and need to be developed within the framework of other activities.

The basic variants of decompression assumptions may include:

- effort,

- thermal comfort.

It is necessary to always take into account the possibility of additional, unforeseen work, for example related to changes of the hydrological situation necessitating work against the water current. In addition, the effort expended can lead to an imbalance in thermal comfort. For example, if divers have prepared themselves to expend light effort in cold water by wearing appropriately selected thermals, they may overheat in conditions of intense effort. Thermal comfort can also be lost by crossing the thermocline 48 or as a result of prolonging the stay under water. Previously performed effort, lack of sleep, slight infections, overcooling or overheating are often the cause of faster hypothermia in the diver. Overheating usually occurs before diving 49 , which later results in a more rapid cooling under water. This is especially relevant to a standby diver prepared for immersion and waiting at the waiting position, therefore, it is necessary to pay attention to his/her protection against overheating, as during the rescue operation the diver may become so exhausted that he or she will only increase the risk.

The effect of excessive, long effort during diving or before diving on decompression has already been highlighted. Thermal comfort also has a significant impact on the safety of decompression. During decompression, the state of saturation with gases is maintained in a metastable equilibrium. Each temperature change causes the disturbance of this equilibrium. Both, cooling during diving and surface decompression in a warm decompression chamber, as well as overheating during diving and decompression under cold conditions cause disturbances of this balance, which may lead to the occurrence of symptoms of decompression sickness DCS.

The main variants of conducting decompression include:

- $\quad$ response to the contamination of the breathing mix,

- reaction to deviations in the composition of the breathing mix,

- acceleration of the decompression process,

- interrupting the decompression process,

- execution of surface and compensatory decompression,

- accumulation of decompression time at deeper stations,

- extension of the decompression process Contamination of the breathing mixture is always undesirable. The problems related to such contamination have been previously described and will not be analysed in this study [8]. In regeneration devices, carbon dioxide (CO2) retention and dust emitted by the filling of the absorbent are frequent hazards. Exhaled carbon dioxide 
(CO2) may accumulate in the respiratory space as a result of an absorbent either being of a poor quality, not changing the medium frequently enough, or the effect of 'channelling' where the breathing medium slips through the filter bed without coming in to contact with adequate amounts of the absorbent, etc. It is advisable to seek cooperation with a supplier who guarantees that the required quality of the sorbent will be maintained.

Furthermore, adequate laboratory control over the stored sorbent should be maintained. These issues will not be part of the project, but the established SOP procedures $^{50}$ resulting from previous work will be maintained and revised as necessary [9]. Sodium lime dusting is associated with its form. Sometimes it is tableted and highly resistant to abrasion and breakage, other times it is loosely formed in various extrusion shapes [10].

A non-dusting form has also been introduced where the sorbent is stabilized in a substrate made of plastic. However, the most common form available in the market is crushed lime which has been sorted (in terms of size of granules) on screens. Such a form is susceptible to dusting the particles due to mechanical shocks, e.g. during transport or packing of scrubbers. For this reason, the sorbent should be dedusted initially on the screens before packing into scrubbers and then on the screens the scrubber should be air washed. During transport of the prepared apparatuses, the lime in the scrubber may be subject to shock and crushing. This phenomenon is accompanied not only by dusting, but also by the formation of passages enabling the regenerated breathing mix to pass through the scrubber without sufficient purification. It is therefore necessary to ensure careful transportation of the rebreathers. Soaking the internal layers of the breathing tubes can be a protection against dust by forming a water film on the internal surface of the tube to which the dust emitted by the filter can adhere. CO2 sorbents are usually a mixture of highly caustic hydroxides and can cause micro burns in the respiratory tract. Due to the possibility of lumping, the sorbent is stored in a dried form, which has a lower $\mathrm{CO} 2$ chemisorption efficiency. That is why before use it should be moistened by performing several exhalations into the scrubber. Soaking the tubes also creates an environment to activate the filling of the scrubber. Partial depletion of the sorbent can occur when it is stored in partly unsealed containers or a filter. Additionally, insufficient water tightness of the device may cause the formation of a highly corrosive hydroxide solution during diving, which in turn may cause severe burns to the respiratory tract.

Carbon dioxide accumulated in the circulating breathing mix causes a number of adverse effects, such as: toxic effects, increased respiratory action, constriction of blood vessels ${ }^{51}$ in the periphery of the body, relaxation of blood vessels in the brain causing an increase in cerebral blood flow, which leads to a greater sensitivity to the central form of central oxygen toxicity CNSyn [4].

The impact of a general change in the breathing mix composition on decompression was discussed in the context of isobaric decompression and counter-diffusion phenomena. When designing hyperbaric exposures, especially decompression schedules, it is extremely important to take into account the existing fluctuations in the composition of the breathing mix inhaled by the diver. This is particularly important for semi-closed circuit rebreathers, where fresh premix is dynamically mixed with regenerated breathing mix.

Even with oxygen decompression, it is never assumed that the diver will breathe with pure oxygen. Nowadays, high purity oxygen ${ }^{52}$, can be used because it is available at a reasonable price, but such a gas allows for decompression in open-circuit apparatuses ${ }^{53}$. In diving devices with a semi-closed circuit there are problems with effective ventilation of the breathing space with oxygen and washing out from the body the inert gases accumulated in the circuit of the breathing mix inhaled by the diver. Therefore, the issues of ventilation must take into account these phenomena and the assumptions related to the effectiveness of the ventilation process must be validated during experimental dives. The issues of SCR CRABE SCUBA's respiratory ventilation with both premix and oxygen are key issues for the project and are thus the main focus of research. In the project it was necessary to take into consideration:

- time of breathing from the rebreather on the surface before the start of the diving process,

- effectiveness of ventilation of the breathing space with fresh premix during the process of descent,

- the influence of body cleansing from inert gases ${ }^{54}$ on the composition of the breathing mix inhaled by a diver,

- effectiveness of washing the respiratory space with a fresh premix during the stay on the bottom $^{55}$,

- effectiveness of washing the respiratory space with fresh premix before starting the ascent process,

- necessity to wash the respiratory space with fresh premix at decompression stations,

- effectiveness of the process of exchanging the breathing mix with oxygen before commencing oxygen decompression,

- necessity to wash the breathing space with fresh oxygen at oxygen decompression stations.

The ventilation model of the breathing space of the SCR CRABE SCUBA is the main basis for planning safe hyperbaric exposures and subsequent decompression. The evaluation of the effectiveness of the ventilation process should be continued during training on a hyperbaric simulator, where reliable data from the diving process can be collected. The database of conducted dives provides the basis for progress building through knowledge and an important element of diving safety monitoring, on which the periodic safety analysis of diving operations should be based. The effectiveness of flushing the breathing space of a diving apparatus is an important element in assessing the training of divers. The ability to use the procedures for flushing the breathing space of the diving apparatus should be periodically checked during mandatory training on a hyperbaric simulator.

The most common procedure used to accelerate the decompression process is oxygen decompression. It is commonly believed that such an acceleration constitutes a 2.5-fold reduction of decompression time using an operating mixture [11-12]. For safety reasons, this parameter should be determined for a specific case of its use or rounded up to simplify the system ${ }^{56}$. However, rounding leads to less effective ${ }^{57}$ decompression schedules, hence there may be a need to generate two or more tables, for example: school, training, combat used for exercises, combat used during warfare, extreme used in anti-terrorist operations, etc., differing in the risk of an occurrence of symptoms of decompression sickness (DCS) or central oxygen toxicity (CNSyn). 
Decompression acceleration may concern emergency situations, such as the need to bypass some decompression stations in case of injury or loss of breathing mix. This must be combined with an appropriate compensatory action. Compensatory decompression may involve oxygen exposure in normobaric or hyperbaric conditions, as in the case of the use of surface decompression procedure ${ }^{58}$. Further development of this issue and of the accumulation of decompression time at deeper stations will be discussed in the context of implementation of the decompression process.

In order to increase safety, the Polish Navy traditionally adopts several scenarios for which the decompression process is extended ${ }^{59}$, i.e.:

- performance of hard work underwater by a diver,

- diver's feeling of coldness during diving and decompression,

- when a dive is one in a series of dives,

- when the diver is untrained or has an individual predisposition to develop decompression sickness (DCS),

- $\quad$ when the diver is obese or his/her body weight exceeds $80 \mathrm{~kg}$.,

- $\quad$ when the diver is over 40 years of age.
If one of the above difficulties is diagnosed, the conservatism of the approach to decompression is increased by using extended decompression. Extended decompression is based on adopting the next, longer diving time from the table for the same depth ${ }^{60}$. If two of the above circumstances occur, the diving time is increased by moving two lines down. In the case of a greater number of impediments, these are not taken into account and are treated as if there were only two of them. Therefore, the last two lines of the allowed stay times at the bottom, for each depth appearing in the decompression table, play the role of emergency times used only in the extended decompression procedure. Attention is also paid to other factors influencing the increase in the risk of occurrence of the symptoms of decompression sickness DCS - tab. 1 .

The task of the project was to develop technologies for point diving. This approach requires both the development of diving technology with planned effort ${ }^{61}$, posing a potential risk of developing symptoms of decompression sickness DCS, and technology taking into account the lack of any additional work by the diver, where the main problem is the risk of developing symptoms of central oxygen toxicity CNSyn.

The main factors that can lead to decompression accidents

1. Reduced blood circulation due to: obesity, hypothermia, physiological decrease of circulatory efficiency (e.g. in elderly people), previous cardiovascular or diving related medical conditions, mechanical pressure (e.g. by diving suit, lack of position changes during decompression) etc.

2. Increase of carbon dioxide content in the inhaled respiratory factor or its accumulation in the body (hypercapnia) caused, inter alia, by: the diver's poor condition, effort, occurrence of dead spaces in the diving equipment, high density of the breathing mix, etc.

3. Considerable effort prior to diving and muscle acidification resulting from the effort. It is recommended to take 3-6 hours rest before diving (depending on the anticipated conditions of proposed dive), and an absolute prohibition of diving by a fatigued diver.

4. Consumption of alcohol prior to diving and before decompression completion (also during compulsory rest on the surface following diving, during isobaric surface decompression). Alcohol reduces the surface tension of the blood, thus facilitating the formation of gas bubbles. It is recommended that 12 hours before and 12 hours after diving, divers refrain from drinking beverages containing alcohol.

5. Dehydration (dehydration) is often trivialised as a factor that may cause decompression problems. Ignoring dehydration can, however, lead to the occurrence of decompression problems despite adherence to other recommendations. Most often dehydration occurs in the following cases:

- For prolonged diving in saltwater in a wetsuit. In this case, water is lost through osmosis (particularly important when using suits with open system water heating).

- Hydrostatic pressure can cause increased diuresis.

- Overcooling of the body can cause increased diuresis.

- During breathing with a dry breathing mix, dehydration occurs as a result of evaporation.

- Caffeine, theine and alcohol cause increased diuresis.

- Some groups of drugs cause dehydration and many cause increased diuresis. Divers may only take medication under the supervision of a doctor.

- Fear and nervous tension can cause increased diuresis.

Raising of the level of fluids in the body (rehydration) is advisable in order to increase the safety of diving. For this purpose, it is recommended to administer mineral water, vitamin water or fruit juices in limited amounts. A diver should drink a lot of fluids several hours before diving. The pre-diving hydration should take into account the diving conditions. It is not always possible to pass urine freely during diving or decompression. If the diver is decompressed in a dry chamber with the possibility of urination, fluids should be administered also during decompression.

6. Injuries such as tissue discontinuity. In the affected areas, a free gaseous phase can form, not only in the obvious cases of pulmonary barotrauma, but also in the case of minor skin injuries.

7. Diving with symptoms of poor physical and/or mental predisposition, e.g.: symptoms of hangover, sleepiness, fatigue, symptoms accompanying menstruation, headaches, signs of illness, etc. They reduce the concentration of attention and thus create the possibility of a mistake, e.g. when controlling the decompression profile, measuring the depth or time of stay, etc. 
The main factors that can lead to decompression accidents

8. The use of vitamins, anti-headache medication, oral contraceptives, stimulants or stress relievers, active plantbased medication, e.g. herbal teas, may not be recommended before diving. One of the reasons for the harmful effects of such agents may be "contamination" by maintaining high concentrations of chemicals in the blood. This may lead to an easier formation of a free gas phase in the blood. Some chemicals such as alcohol (alcohol is a component of many liquid drugs, e.g. cough syrups) cause a change in the surface tension of blood, thus facilitating the formation of a free gas phase in the blood.

9. It is important to pay attention to various types of implants and even fillings of treated teeth. Cases of toothache induction with wrongly fitted or wrongly selected fillings are known. In such cases, it is recommended to consult one's doctor about the possibility of diving, and during the treatment of teeth, it is necessary to inform that diving is practiced.

\section{ORGANISATIONAL CONTEXT}

In the implementation of independent dives in the marine environment by the Polish Navy, for the classic decompression designed with decompression stations every $3 \mathrm{mH} 20$, the diving technology should ensure the emergency decompression process with the possibility of having the last decompression station at a depth of $6 \mathrm{mH} 20$. Such a procedure may be useful in the case of changes in wave height in the diving area or in the event of diving in locations with high average wave heights. In such a situation, the possibility of a diver remaining at the station depth of $3 \mathrm{mH} 2 \mathrm{O}$ is problematic. For organisational reasons, it is best to assume that the duration of the emergency decompression process should be the same as for the basic decompression and the stay at the $6 \mathrm{mH} 2 \mathrm{O}$ station should be the sum of the stay at the $3 \mathrm{mH} 2 \mathrm{O}$ and $6 \mathrm{mH} 2 \mathrm{O}$ stations.

The Polish Navy has traditionally required that the decompression system should permit to compensate for difficult decompression transition conditions, allow for surface decompression, provide for compensatory decompression, etc. Such a system should consist of hyperbaric procedures, including therapeutic procedures, and provide the required technical and medical equipment to carry them out. The system should be supplemented with a subsystem for evacuation of injured divers to a specialist hyperbaric centre or hospital. The elements of the system securing the realisation of therapeutic processes can be borrowed or developed anew and dedicated especially to the system of conducting diving works. Due to the use of autonomous SCUBA equipment, the system of therapeutic recompression tables TT62 should provide for therapeutic procedures in case of a diver being "thrown" from considerable depths bypassing decompression stations and, as a result, explosive decompression.

The use of semi-closed circuit SCR diving apparatus and mixtures with increased oxygen content requires the development of a recruitment process for divers and maintaining those divers in good physical condition. The system must take into account the health parameters of the divers. The assumption here is that they will be compatible with the requirements for military divers. Additional criteria can also be added to the qualification process ${ }^{63}$. The adopted standard of physiological parameters of a diver is a guideline for the development of a procedure for the implementation of an effective decompression process.

A higher level of risk of developing symptoms of decompression sickness (DCS) than would be considered acceptable for recreational divers was assumed for this decompression process ${ }^{64}$. The system may also include procedures for decompression as for recreational divers, which will be used during training.

Due to the fact of development of technology for the diving process using semi-closed circuit rebreather (SCR), it should include developed and validated effective procedures for the process of breathing space flushing. The technology should assume that there will be no need for the implementation of the breathing space flushing process while at the bottom. However, an effective flushing procedure can always be used in the case of a suspected loss of control over the composition of the breathing mix that the diver is breathing. These procedures increase the oxygen content in the circuit and their effect on the possibility of occurrence of central oxygen toxicity (CNSyn) should be investigated.

An important parameter of a diving operation is the ability to burden the diver with work. The value of workload is related to the process of ventilating the breathing space of the rebreather, as well as to the process of decompression and increasing risk of central oxygen toxicity (CNSyn). In this case, medium-heavy ${ }^{65}$ workload and rest 66 . have been assumed. The influence of thermal protection of a diver on the decompression process must also not be overlooked.

Risk analysis shows the need to use emergency breathing subsystems. Emergency breathing systems may be based on the possibility of transitioning to breathing from an integral cylinder set using a redundant 67 breathing system. This process prevents loss of control over the main respiratory system and not the loss of breathing mix reserve. From the perspective of planning the exposure process and subsequent decompression, the use of an emergency respiratory system with a different mode of action from that of the main system should take into account variations in the risk of CNSyn. If it is considered necessary to develop procedures for the use of respiratory systems independent of the rebreather used 68 account should also be taken of the phase of diving for which transition to emergency decompression will be possible.

In order to secure the described basic and emergency processes, it is required to develop a minimal system ${ }^{69}$ consisting of:

- $\quad$ procedures for qualification for diving with the intended rebreather and breathing mixtures,

- a specially designed and validated procedure for basic decompression, together with the rules for the workload of the diver,

- specially designed and validated emergency decompression procedures,

- $\quad$ procedures for flushing the breathing space of the diving apparatus, taking into account the 
increased risk of developing symptoms of central oxygen toxicity CNSyn,

- borrowed or newly developed therapeutic procedures in the event of an occurrence of diving sicknesses (DCI),

- hyperbaric and medical equipment to secure the process of treatment of DCI and other possible cases,

- transport subsystem to a hyperbaric facility,

- procedures for estimating the risk of CNSyn,

- an integral emergency breathing subsystem of the rebreather,

- emergency rebreathers,

- diver thermal protection subsystem.

If the requirement for acceleration ${ }^{70}$ of the basic decompression process by using oxygen at the last decompression stations is introduced, the system must be further extended not only by a validated procedure for the oxygen decompression process, but also by the elements resulting from the risk analysis carried out for this process.

The decompression procedure will need to determine at what stage it is safe to transition to oxygen decompression due to past exposure and increased oxygen partial pressure, taking into account the resulting increase in the risk of central oxygen toxicity (CNSyn). Regardless of the time and depth of the transition to oxygen decompression, an effective procedure should be sought for the process of ventilating the breathing space of the rebreather with oxygen.

The decompression acceleration algorithm will depend directly on its effectiveness. Of course, it is necessary to consider the procedure of switching from oxygen decompression to decompression using a gas mixture at any time ${ }^{71}$. It is best if the decompression time between the decompression process using a respiratory mixture and oxygen is calculated according to a simple rule. In this case, it is sufficient to specify the duration of the stay at the stations for the basic decompression schedule using oxygen decompression. Emergency decompression using a breathing mixture will be the calculation of the time spent at stations breathing oxygen. The change of the breathing mix during decompression will require the development of rules for flushing the breathing space of the device. In case of a failure of the oxygen supply from the rebreather, it is also possible to consider extending the system with external oxygen breathing systems ${ }^{72}$.

The use of an oxygen decompression system and emergency decompression when breathing the circulating breathing mixture may become complicated if the requirement for marine systems, with the last decompression station at $6 \mathrm{mH} 20$, is maintained. Such a requirement for all decompression schedules may make the primary decompression process too conservative and thus ineffective from the point of view of military diving operations. In this case, it is possible to dispense with this requirement for emergency decompression and to develop two decompression systems depending on whether or not the dive will be protected by other oxygen sources in the event of a malfunction in the supply from the integral cylinder set of the rebreather.

For marine systems, it seems attractive to use the surface decompression process. For some decompression stations, the process of surface decompression enables interruption of the decompression process in water, rapid ascent and entering the decompression chamber. Then the compression and completion of the rest of the decompression is performed on the surface in the decompression chamber. Such a procedure reduces the diver's risk associated with being underwater, but exposes the diver to stress associated with interrupting the decompression process. Evidence shows that interruption of decompression can last up to $7 \mathrm{~min}^{73}$. It is a relatively short time for ascent, reaching the decompression chamber, partial removal of the diver's gear and recompression. Surface decompression systems, as the basic procedures for the decompression process, are used for tethered dives, carried out from a surface platform equipped with a decompression chamber ${ }^{74}$. For independent dives, such procedures only serve emergency functions.

The system for conducting underwater works may not provide for repetitive dives, but should normalise the rest time that should elapse before the next dive.

\section{CONTEXT RELATED TO EQUIPMENT}

The most used mixture for supplying open-circuit apparatuses is the premix, which fills the cylinders supplying the demand regulator, although it is possible to have designs that produce the breathing mix during the diving process from gas components 75 . One of the options to consider is an open-circuit apparatuses supplied with air and oxygen, which adjusts the oxygen content $x_{i}$ in the dynamically composed air-oxygen mixture depending on the diving depth $\mathrm{H}$, similarly as for semi-closed-circuit rebreathers, e.g. the Polish SCR KSZYK SCUBA [13]. In such a case it is necessary to know the function realising the algorithm of mixing gases from components $x_{i}=f(H)$ and to assess on the basis of oxygen content $x_{i}$ its partial pressure $p_{i}$ as well as the partial pressures of other gases $\left(p_{1} . . p_{0}\right)$. The partial pressure of oxygen $p_{i}$ and other gases $\left(p_{1} . . p_{.}\right)$is the basis for estimating decompression, exposure to various forms of oxygen poisoning and toxic effects of gases ${ }^{76}$.

The situation will become more complicated if the types of breathing mixes are changed during the diving process ${ }^{77}$. In this case, the possibility of counter-diffusion, including isobaric, should be taken into account. Both the composition of the breathing mix $\left(\mathrm{x}_{1} . . \mathrm{x}_{\bullet}, \mathrm{x}_{\mathrm{i}}\right)$ and the partial pressures ${ }^{78}$ of its components $\left(\mathrm{p}_{1} . . \mathrm{p}_{.}, \mathrm{p}_{\mathrm{i}}\right)$ for the different types of rebreathers can represent complex functions of depth $H:\left(x_{1} . . x_{0}, x_{i}\right)=f(H),\left(p_{1} . . p_{.}, p_{i}\right)=$ $=\mathrm{f}(\mathrm{H})$.

Open-circuit apparatuses adapt to the breathing action of the diver, hence the limitations of workload $W$ are related to the training of the diver and the constraints of the breathing system. However, it is not advisable to plan for heavy effort 79 during independent and tethered dives outside the saturation zone for the reasons given above.

In closed-circuit rebreathers, in addition to maintaining the composition of the breathing mix $\left(x_{1} \ldots x_{\bullet}, x_{i}\right)=f(H, t)$,va function of depth $H$ and time $t$, the reliability of the algorithm for maintaining the partial pressures of gas components of the breathing mix $\left(p_{1} . . p_{.}, p_{i}\right) \cong$ idem in response to forced actions is important. For example, to changes in the consumption of oxygen $\dot{V}$ as a result of a change in workload $W$ necessitating most often ${ }^{80}$ changes in the oxygen stream $\dot{V}_{i}$ dosed into the respiratory circuit: $\dot{V}_{i}=f(\dot{v})$.

The devices of this type are designed in such a way as to economize on the supply of the breathing mix, 
hence they have to be able to react moderately quickly to forced action. Otherwise, minor fluctuations in the maintenance of a certain depth $\uparrow \mathrm{H} \downarrow$ could result in an unjustified loss of the breathing mix. Hence, deviations from the stable oxygen content statex $_{\mathrm{i}} \neq \mathrm{idem}$, for example with rapid changes in the workload $81 \mathrm{~W}$, may cause instability in the algorithm for maintaining the composition of the inhaled breathing mix $\uparrow\left(\mathrm{x}_{1} . . \mathrm{x}_{\bullet}, \mathrm{x}_{\mathrm{i}}\right) \downarrow$, thus posing an additional risk. The algorithm used in closed-circuit rebreathers is ideal for sustained light effort. Therefore, even with the use of combat oxygen devices, it assumes planning rather low speed of movement during a combat mission. The planned effort should be relatively constant, both based on purely mechanical or electronically controlled mechatronic actuators ${ }^{82}$, so that the system of supplementing the deficiencies in oxygen $x_{i}=f(\dot{v}, H)$ or the breathing mix $\left(x_{1} \ldots x_{0}\right)=f(H)$, was able to correctly interpret the situation and respond with an adequate action.

In a semi-closed circuit rebreather, fresh breathing mix is dynamically mixed with the regenerated one. Determining the function $\left(x_{1} . . x_{j}, x_{i}\right)=f(\dot{v}, H, t)$ of the composition $\left(\mathrm{x}_{1} \ldots \mathrm{x}_{\bullet}, \mathrm{x}_{\mathrm{i}}\right)$ of the breathing mix inhaled by the diver depending on the consumption of oxygen $\dot{v}$, depth $\mathrm{H}$ and exposure time $\mathrm{t}$ is a fundamental problem when planning safe hyperbaric exposure and subsequent decompression. Most often such devices perform a predefined function to obtain the composition of the $(\dot{\mathrm{v}}, \mathrm{H})$ mechanically ${ }^{83}$. Predefining an algorithm to maintain a constant, assumed composition of the breathing mix inhaled by a diver $\left(\mathrm{x}_{1} \ldots \mathrm{x}_{\bullet}, \mathrm{x}_{\mathrm{i}}\right)=\mathrm{f}(\dot{\mathrm{v}}, \mathrm{H})=$ const requires the adoption of assumptions concerning the individual parameters of a diver $\theta$ and the permitted tolerances for deviations from these values $\Delta \theta$. Subsequent selection of divers, requires checking the fulfilment of the assumptions underlying the design of the algorithm for maintaining the assumed composition of the breathing mix inhaled by the diver $\left(\mathrm{x}_{1} \ldots \mathrm{x}_{\mathrm{j}}, \mathrm{x}_{\mathrm{i}}\right)=\mathrm{f}(\dot{\mathrm{v}}, \mathrm{H})$.

The assumed individual parameters $\theta$ do not always have to be met by a diver, especially when accompanied by such phenomena as: sports vagotonia ${ }^{84}$, bradycardia 85 , significant muscle tissue development, being overweight or underweight, etc. Hence divers should be initially classified to diving using semi-closed circuit rebreathers with regard to the fulfilment of the assumed individual parameters $\theta$ when designing the device and diving technology.

Individual parameters of divers $\theta$ change with the age and the degree of his/her preparation/training. Annual medical screening does not focus on these changes. Its task is to check the general state of health and not the level of training or fulfilment of individual parameters $\theta$ being the basis for the safe use of diving apparatuses. Therefore, one-time certification to dive with special diving devices may no longer be justified as divers age, or if their training is not kept up to date86. It seems good practice to check the essential for safety individual parameters of a diver $\theta$ during each training course to obtain higher diving qualifications.

In the process of diving safety analysis in the Navy of the Republic of Poland, it is crucial to properly prepare the dive in terms of the diver's condition, efficiency and decompression, because the individual parameters of a diver $\theta$ sometimes undergo significant fluctuations as a result of adaptation training or its discontinuation. Control of individual parameters of a diver $\theta$ is possible during mandatory training using hyperbaric exercise simulators, preferably hyperbaric swimming simulators ${ }^{87}$, as part of the prevention of potentially dangerous situations.

The level of diving safety is closely related to the risks posed by the equipment and technology used 88 .

The presented project focuses on elements of the diver's equipment, i.e. the SCR CRABE SCUBA rebreather and the resulting risk of decompression sickness (DCS) and central form of oxygen toxicity (CNSyn), in the tactical context of MCM mine-warfare. Important elements of the diving equipment, include $\mathrm{XBS}^{89}$, diving suits ${ }^{90}$, gas analysers ${ }^{91}$, decompression meters, etc.

\section{TACTICAL CONTEXT}

In military diving, the use of diving equipment as structural components of a system ensuring the implementation of processes resulting from the adoption of specific tactics ${ }^{92}$ plays a dominant role. In the understanding of the tasks of the described project, dives constitute an element of the system aimed at ensuring the protection of our own forces and public safety, which can be divided into three subsystems: MCM93, EOD ${ }^{94}$, and IEDD ${ }^{95}$.

MCM activities are processes implemented in the mine-warfare System. The elements of the mine-warfare system are specialised vessels, traditionally divided into two groups: mine sweepers and mine hunters, but nowadays this division has become blurred and it can be assumed that in modern navies there is a single class of vessels used in this respect, i.e. MCMV 96 . The first of these are the traditional minesweepers, which, when passing over the minefield, drag the trawls that simulate the physical fields of ships, forcing mine explosions or undercutting an anchor mine and shooting it on the surface. The second type of vessel has developed into an MCMV and is a comprehensively equipped vessel for the implementation of mine searches and neutralisation processes, in particular intelligent mines. Typically, MCMVs are equipped with autonomous $\mathrm{AUVS}^{97} / \mathrm{UUVS}^{98}$ for reconnaissance in order to collect on a digital map potential targets that can be neutralised by other autonomous AUVs or ROUVs ${ }^{99}$. Such vehicles can carry special explosives for neutralisation of suspicious objects, 'bombard' them with the use of dedicated explosives detonated remotely after the vehicle has entered a safe area, or with a self-propelled explosive charge.

Most commonly, a ship is also equipped with an ROUV fitted with various sensors to scan the basin ahead of the ship 100 and a towed system equipped with similar sensors for scanning the seabed. Such a vessel may be equipped with an intelligent trawl system simulating physical fields of different classes of ships. It is most often towed by an MCMV-based surface unmanned ASV101. The ship is a part of the network-centric ${ }^{102}$ system of larger anti-mine forces ${ }^{103}$. Such units usually have divers prepared to carry out rescue operations ${ }^{104}$ and serve as one of the elements of mitigating the threat from sea mines.

It is possible for MCM divers to perform dives from small vessels operating from the shore or carried by ships ${ }^{105}$. Their tasks may include reconnaissance, less often liquidation or partition of defence infrastructure of hydrotechnical objects or bank reinforcement ${ }^{106}$.

In the part concerning MCM activities, the presented project focuses on rescue operations of MCM equipment, neutralisation of intelligent mines and the 
blinding of electronic defence infrastructure of maritime objects.

The EOD activities focus on the elimination of dangerous explosives, in the form of undetonated military explosives $\mathrm{UXO}^{107}$ as remains from: wars, bases, military exercises, etc. Owing to the related risk, these activities are treated as combat activities carried out in conditions of peace ${ }^{108}$. An important variation of these activities are IED operations focused on counteracting UXO not recognised as typical military equipment. At least theoretically, EOD operations pose less of a threat, because the way of proceeding results from catalogued algorithms of handling UOX of military origin, which typically have the possibility of deactivation when set to being irremovable, or the defence system of an intelligent object.

Unfortunately, even relatively primitive IEDs can be irremovable otherwise than by their controlled detonation, and the only countermeasure to reduce the impact is to rapidly divert the shock wave in a different direction ${ }^{109}$ or to use protective screens ${ }^{110}$. In some cases it is possible to use jamming 111 against the electronic devices applied, however often these are relatively primitive electrical devices, which can be deactivated only mechanically, for example by shooting them with various kinds of bullets ${ }^{112}$ from a cannon or with a cumulative EFP charge ${ }^{113}$, burning with a thermite charge, melting of an explosive material, etc. The project by its nature is connected with the MCM and EOD activities, omitting the IED activities, as the IED is closely related to the parameters of physical fields generated by diving equipment and is not strictly related to the diving technology, although the processes of flushing the breathing space of the device are extremely important from the point of view of emitting noise into the body of water.

From a tactical point of view, risk analysis is aimed at accepting levels of threat other than the levels resulting from the risk analysis of diving operations. This is obvious as both approaches relate to different objectives. However, the tactical planning of diving operations must also take into account the conditions of the diving technology. For example, for a hypothetical scenario of an operation to land members of the armed forces at a specific location. the analysis of the risk of a hidden reconnaissance operation and the possible preparation of separation of underwater minefields by divers, from a tactical point of view, is aimed at determining the probability of effective performance of the task at the assumed level of confidence 114 .

The protection of navigable waterways should be implemented safely and quickly. It is not always possible for MCMV units to be called in to deal with drifting mines observed by vessels which themselves are not equipped to deal with the task. In this case, typical drifting mines may be cleared by VSW divers/swimmers 115 , who, operating from helicopters, and may be dropped into the water and place a remotely activated charge in the proximity of the drifting mine ${ }^{116}$ or on it. Intelligent mine countermeasures on a navigable route cannot always be achieved by underwater vehicles or self-propelled charges on account of the region or the expected operation of the mine117. Since vehicles are more easily and more likely to be detected by the sensors of such mines, the use of divers remains, as they have a high possibility of masking themselves against the background of normal physical fields occurring in the water. A diver can precisely set a small, non-electrically ignited cumulative charge, cross- wire a mine until it is detonated by a self-propelled charge or prepare it for towing.

Underwater IED activities are practically always carried out by VSW swimmers or divers.

Counteracting terrorist attacks or actions in asymmetric conflict where suicide divers are being used is based on the use of unmanned equipment, manned equipment, SRT diving operations, etc. Knowledge of the capabilities of divers in such cases is extremely important, not only to estimate the risk to their own forces, but also the potential of terrorist/suicide divers.

During the implementation of the project data for tactical risk analysis for typical scenarios of underwater operations will be compiled in conjunction with the risk of decompression sickness (DCS) or central oxygen toxicity (CNSyn).

\section{RESEARCH CONTEXT}

At the very beginning of work on decompression systems for diving devices in Poland 118 it was noted that domestic progress is possible only through seeking deterministic models ${ }^{119}$. Consistent adherence to this assumption by three generations of researchers has led to the development of reliable and effective, though arduous, methodology 120 .

In the applied research approach, the methods of predicting the behaviour of the ergonomic diverrebreather system were divided into a number of interrelated models ${ }^{121}$ - fig. 1 . On the basis of the validation studies conducted to date, it seems that the analytical breakdown into partial models does not cause the generation of significant errors in their synthesis into a holistic model and their use according to the holistic approach.

Ventilation modelling by means of differential equations has been known for centuries. These are relatively simple equations that can be solved by mathematical analysis methods. 


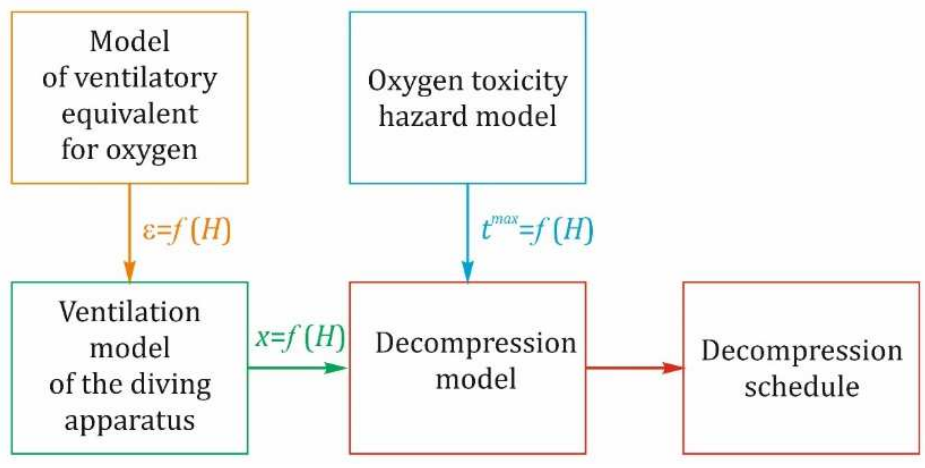

Fig. 1. Model sequence

However, their usefulness until recently was questioned on the grounds that some parameters of these models could not be determined with sufficient accuracy ${ }^{122}$. Therefore, ventilation engineering is based on semi-empirical models derived from the approximate solution of the differential equation by means of dimensional analysis methods.

The barriers related to the use of a deterministic approach to the ventilation process were first overcome about 15 years ago. This made it possible to master the modelling of deterministic ventilation of a submarine, a hyperbaric chamber or a mining pit [14]. The use of these achievements in industrial and sanitary engineering could lead to a change in the approach to ventilation problems.

Earlier studies on ventilation of a semi-closedcircuit rebreather with continuous dosing of the breathing mix were successfully completed about 20 years ago [13]. However, such devices have been withdrawn from national use.

In the current approach to modelling a diving system using the SCR CRABE SCUBA, the initially holistic approach has been replaced by an analytical one. The basis for the planning of decompression schedules is based on several models shown in fig. 1:

- modifications in the breathing module ${ }^{123} \varepsilon$ in the function of depth $\mathrm{H}: \varepsilon=\mathrm{f}(\mathrm{H})$,

- modifications in the composition of the breathing mix inhaled by the diver $\left(\mathrm{x}_{1} \ldots \mathrm{x}_{\mathrm{j}}, \mathrm{x}_{\mathrm{i}}\right)=$ $\mathrm{f}\left(\mathrm{H}, \varepsilon, \varepsilon_{\mathrm{k}}, \mathrm{x}_{\mathrm{w}}, \mathrm{t}\right)$ depending on: depth $\mathrm{H}$, breathing module $\varepsilon$, design parameters for a semi-closed breathing space of a rebreather $\varepsilon_{\mathrm{k}}$, premix composition $\mathrm{x}_{\mathrm{w}}$ and time $\mathrm{t}$,

- changes in the hazard of central oxygen toxicity CNSyn depending on oxygen partial pressure $\mathrm{p}_{\mathrm{i}}$ and exposure time $\mathrm{t}$,

- designing decompression ${ }^{124}$ as a function of hyperbaric exposure time $t$ and pressure $\mathrm{H}$, taking into account the influence of interfering factors such as temperature $\mathrm{T}$, the influence of previous exposures on decompression, increased risk of central oxygen toxicity CNSyn, additional workload $\mathrm{W}$, immersion and ascent sequence, transport to the place of immersion, stress load before and after diving, etc.

The function $\varepsilon=\mathrm{f}(\mathrm{H})$ of changes in the breathing module ${ }^{125} \varepsilon$ depending on the depth $\mathrm{H}$ is not crucial for the reliability 126 of determining the values of stable oxygen content $x_{\mathrm{s}}$ from the ventilation model. It has become significant because unexpectedly the other models shown in fig. 1 are determined with much greater reliability. When searching for solutions for the differential ventilation model of a rebreather containing a system of bags placed one in the other $\frac{\partial}{\partial t}\left(x_{1} . . x_{j}, x_{i}\right)=f\left(H, \varepsilon, \varepsilon_{k}, x_{W}, t\right)$ the breathing module $\varepsilon$ began to play a key role127. This made it necessary to conduct research on the reliable determination of the dependence of the breathing module $\varepsilon=\mathrm{f}(\mathrm{H})$ on depth $\mathrm{H}$.

The studies of the breathing module $\varepsilon$ are described in the available literature with respect to atmospheric pressure, as they constitute an important indicator of athletes' training and form the basis for many studies concerning effort medicine or work standardisation [15]. The hitherto uncritical transposition of values for normobaric conditions into hyperbaric studies was a barrier to an adequate development of diving systems. The results of studies concerning the breathing module $\varepsilon$ in specific hyperbaric situations can be found in rare specialist publications [5-6]. However, the application of these values is still associated with a decrease in the required accuracy and precision of ventilation modelling. Determination of the relationship $\varepsilon=\mathrm{f}(\mathrm{H})$ regarding changes in the respiratory module $\varepsilon$ as a function of depth $\mathrm{H}$ for predefined conditions was performed by conducting experimental exposures in simulated conditions on a representative group of experimental divers ${ }^{128}$.

The ventilation model allows to determine the stable oxygen content as a function of depth: $\mathrm{x}_{\mathrm{s}}=$ $\mathrm{f}(\mathrm{H}) \mid \mathrm{x}_{\mathrm{s}}(\mathrm{H}, \mathrm{W}) \equiv \mathrm{x}_{\mathrm{i}}=$ idem, environmental parameters and effort. After considering the fluctuations encountered $\Delta \mathrm{x}_{\mathrm{s}}$ in a stable oxygen content $\mathrm{x}_{\mathrm{s}}$, for a predefined depth $\mathrm{H}$ and workload $\mathrm{W}$, the model constitutes a contribution to decompression modelling - fig. 1.

In semi-closed circuit rebreathers SCR supplied with premix, there is a relative decrease in oxygen content 129 from the concentration in the premix $x_{W}$ to a stable value ${ }^{130} \mathrm{x}_{\mathrm{s}}$. This phenomenon is caused by obtaining the equilibrium condition when the regenerated mixture is mixed with the fresh one. The dynamics of this process can be modelled similarly to other ventilation processes [14]. Based on previous longstanding studies, it can be concluded that the ventilation process of the SCR CRABE SCUBA rebreather can be described in sufficient detail based on the ideal gas law. The differential equation built on the basis of the molar balance can be accurately calculated. Such an approach is not widely used owing to the difficulties encountered in establishing certain parameters for this equation. Through many years of research on the process of ventilation of submarines, 
hyperbaric chambers, mining pits, etc., it was possible to propose a reliable approach to this issue, hence the modelling was based on a fully deterministic, algebraic analytical model.

Research into the process of rebreather ventilation without human participation is carried out using a station of accumulated simulators of: metabolic oxygen consumption $\dot{v}$, respiratory action $\dot{V}_{\mathrm{E}}$ and depth $\mathrm{H}$. The simulator is, in many respects, an original solution on a world scale created as a result of many years of own research. It is distinguished by the fact that a liquid medium is used to simulate oxygen consumption $\dot{v}$, and not a gaseous one as in other similar technical solutions in the world [16]. Because of this, adding it negligibly disturbs the volume of gases in the ventilated space. The simulator set-up features an extremely short pathway between the pump simulating lung ventilation $\dot{\mathrm{V}}_{\mathrm{E}}$ and the tested respiratory system, which does not cause compression and expansion of the breathing mix in the line inducing respiratory action.

Concurrently, research is conducted in simulated hyperbaric conditions with the participation of experimental divers. Based on the results of these studies, the reliability of the applied modelling of the ventilation and gas exchange process in the ergonomic diverrebreather system is determined. Studies conducted without the participation of experimental divers give an answer on the credibility of the applied mathematical model in relation to the processes taking place in the real object, i.e. the rebreather. Research with experimental divers allows us to determine the decrease in the reliability of the mathematical model in the course of rebreather ventilation when accompanied by a disturbance associated with the biometric diversity131 of divers HF132, marked here as $\theta$.

While oxygen is needed to maintain haemostasis in humans, it is also a carcinogenic factor. Theories exist that postulate that its effects are the main cause of ageing of aerobic organisms ${ }^{133}$. In hyperbaric conditions, it is more dangerous, revealing some forms of toxicity not found in everyday life. Under hyperbaric conditions, oxygen exhibits pulmonary ${ }^{134}$, central ${ }^{135}$ and somatic toxicity 136 [17-20]. The most serious form of oxygen toxicity in short-term military dives is central toxicity CNSyn.

Experiments with central oxygen toxicity CNSyn often revealed less specific symptoms, such as anxiety, paleness of the face, tremor of the lips and eyelids, nausea, cramps, confusion, lack of coordination, visual and auditory hallucinations, narrowed vision or speech disorders. These symptoms rarely precede the seizure. The onset of generalised convulsions is sudden. The seizure starts with a tonic phase, usually lasting 30 seconds, during which the diver loses consciousness and the respiratory function stops. This is followed by a clonic phase with uncoordinated movements of the whole body. The duration of the whole attack is usually about 2 minutes. If the poisoning has occurred in the water, the safety diver should try to wait until at least part of the consciousness and respiratory action have returned, a period of apnoea of up to 3 minutes can be allowed.

An ascent of a diver without restoring respiratory action may cause pulmonary barotrauma, as oxygen toxicity and loss of respiratory action are usually accompanied by laryngeal clenching. Severe forms of central oxygen toxicity CNSyn are fatal. There are many empirical models in the world to predict the risk of this form of oxygen toxicity CNSyn [21]. The project is based on the widest published systematic research on modelling the risk of central oxygen toxicity CNSyn 137 relying on mathematical survival analysis ${ }^{138}$ [22-23]. The model was adjusted on the basis of the results of studies conducted by the British during World War II [24-25] and their continuation by the Americans until the late 1970s [26]. Our own research on the adequacy of such an approach to central oxygen toxicity CNSyn modelling was completed with the validation of the model established by the US Navy [4].

The estimation of the level of relaxation ${ }^{139}$ following oxygen exposures is most commonly performed using the empirical model ${ }^{140}$ proposed by the Oceanic and Atmospheric Administration [27].

The estimation of safe decompression schedules was based on the abandoned ${ }^{141} \mathrm{ZH}-\mathrm{L}_{12}$ model developed by Bühlmann for the Swiss army [28]. The model takes into account military conditions, such as: the special selection of a group of divers, keeping divers in the condition to undergo strenuous decompression, increased level of approved threat, etc. It can be assumed to be extremely safe. The model was validated during previous studies[2930].

Decompression planning must be based on predicted scenarios for diving operations, safety measures applied ${ }^{142}$, pre- and post-diving rest conditions, transport conditions, etc. The assessment of these parameters can be carried out through experimental dives under simulated conditions, which allows the determination of the permitted ranges of selected exposure parameters. Validation of the approach, as in previous stages of the study, can be achieved by statistical means using sequential analysis [31-32].

The deterministic models of ventilation of the semi-closed respiratory space of the SCR CRABE SCUBA rebreather and decompression presented in Fig. 1, as well as the statistical model of the risk of oxygen toxicity CNSyn were established with such reliability that the empirical model $\varepsilon=\mathrm{f}(\mathrm{H})_{\theta}$ of a change in the respiratory module $\varepsilon$ along with depth $H$ for a selected population of experimental divers $\theta$ as a parameter, became the modelling element with the greatest effect on the safety of conducting a hyperbaric exposure. Selected population of divers $\theta$ was a standard population admitted to military diving in the Polish Navy. Additionally, population $\theta$ should undergo the test for deviations from the function $\varepsilon=\mathrm{f}(\mathrm{H})_{\theta}$ describing changes ${ }^{143}$ in the respiratory module $\varepsilon$ with depth $\mathrm{H}$ as well as oxygen tolerance test TTT [32]. A negative result of the oxygen tolerance test is a premise to plan diving operations only with a lower risk of central oxygen toxicity CNSyn and to take precautions when planning the treatment process using oxy-TT procedures $^{144}$ [32]. In turn, deviations from the established function $\varepsilon=\mathrm{f}(\mathrm{H})_{\theta}$, mean that for safety reasons, the diver should have a differently designed decompression. Negative results of these tests tend to disqualify the diver from diving training with the use of the SCR CRABE SCUBA, for formal organisational reasons ${ }^{145}$.

The ability to continuously improve the precision of decompression planning involves constant improvement of the empirical model $\varepsilon=\mathrm{f}(\mathrm{H})_{\theta}$ for a change in the respiratory module $\varepsilon$ together with depth $\mathrm{H}$. Each dive providing reliable data146 on its course enhances the database to be used in the inference on the precision of determining the function $\varepsilon=\mathrm{f}(\mathrm{H})$ and can be used as a guideline to change the decompression schedule. 
Operational dives cannot provide reliable data for such inference, but training and simulation exercises give such a possibility.

The inference regarding increasing the risk is connected with the diagnosis of deviations from the empirical model $\varepsilon=\mathrm{f}(\mathrm{H})_{\theta}$ of changes in the breathing module $\varepsilon$ with depth $H$. Data collected during training and practice in the diving simulator help to identify divers for whom the decompression procedure may be potentially dangerous. Diver testing on a diving simulator may be used to eliminate DCS hazards. If the results of the research show no deviations from the model $\varepsilon=\mathrm{f}(\mathrm{H})_{\theta}$ and an increased risk of symptoms of decompression sickness DCS is observed, other causes should be sought, for example, deviations from the technology ${ }^{147}$ of conducting underwater works or casuistic reasons ${ }^{148}$. Monitoring of deviations from the empirical model $\varepsilon=\mathrm{f}(\mathrm{H})_{\theta}$ of a change in the respiratory module $\varepsilon$ with depth $H$ is a potential tool of work for an officer responsible for the safety of diving in the Polish Navy.

\section{ProjeCt CONTEXT}

A scientific project is a process that takes place in a system that has the structure allowing its implementation ${ }^{149}$, for which an analysis of internal and external contexts should be carried out.

The objective of the project was the operational need to implement a domestic ${ }^{150}$ diving technology using an independent semi-closed-circuit SCR CRABE SCUBA rebreather as a subprocess of mine countermeasures operations MCM. The analysis of the project context was carried out using the SWOT method ${ }^{151}$. A separate problem will be the analysis of the context of mine warfare for dives using the SCR CRABE SCUBA.

The results of the generation of expected strengths and weaknesses as well as threats and opportunities are presented in tab. 2. Strengths $\mathrm{S}$ include everything that is an asset, advantage or value of the analysed system, i.e. the established research project. Weaknesses W comprise all that constitutes a weakness, barrier or disadvantage of the analysed system. Opportunities $\mathrm{O}$ encompass all that creates an opportunity for the analysed system to make a positive change. Threats $\mathrm{T}$ include everything that creates a danger of an adverse change for the analysed system.

A strength of the project context is the existing research base. Its beginnings date back to the times of the Council for Mutual Economic Assistance, which made the decision on Poland's specialisation in the production of hyperbaric systems ensuring the possibility of conducting long-standing underwater works to a depth of $200 \mathrm{mH} 20$. The main pressure facilities were to be manufactured by the Szczecin Shipyard. The coordination of the research programme for the shipyard was entrusted to the Gdańsk University of Technology. The Polish Naval Academy (AMW), on the other hand, was to be a supplier of life saving systems. In order to ensure financing of such extensive works, Central Research and Development Projects (CPBR) were established. It was soon realised that an important element ensuring the success of the undertaking would be the delivery and acceptance tests entailing the need to conduct saturation dives. At that time, saturation diving technologies were considered strategic and were not rendered available to the public. It was decided to entrust the task of developing such a technology to the Military Medical Academy WAM ${ }^{152}$ which did not have its own technical facilities but cooperated with the Polish Naval Academy.

It was also realised that the possibility of hiring a professional team of divers from outside Poland is related to such a large economic barrier that it was decided to enhance the activities by establishing a separate CPBR division ${ }^{153}$ in which such teams would be trained. This task was entrusted to the WAM-AMW team.

The research carried out at that time and later implementations of the technology contributed to the establishment of a knowledge base for further work in the field of widely understood diving technologies, which were continued also through international cooperation. 
Main strengths $\mathrm{S}$, weaknesses $\mathrm{W}$, opportunities $\mathrm{O}$ and threats $\mathrm{T}$ for internal and external conditions for the implementation of the national diving technology with the use of an independent semi-closed circuit SCR CRABE SCUBA rebreather.

1 research base in place

2 scientific and research potential

3 gained experience

\begin{tabular}{lll}
\hline W & $\frac{1}{2}$ insufficient military service base \\
\cline { 2 - 2 } 2 & inefficient supply system \\
\hline 3 & possibilities of decompression and treatment tables \\
\hline
\end{tabular}

01 enhancement of the required NATO operational capabilities

2 development of a systemic approach to the planning of diving operations

3 plan to modernise the Armed Forces

T $1 \quad$ expected long implementation period

2 need for significant financial resources

3 difficulties in maintaining the sustainability of the project results

S - Strengths: all that is an asset, an advantage, a value the analysed system

W - Weaknesses: all that constitutes a weakness, barrier or disadvantage of the analysed system

O - Opportunities: all that creates an opportunity for the analysed system to make a positive change

T - Threats: all that creates a danger of an adverse change for the analysed system

The acquired knowledge was used to maintain the continuous presence of the AMW service department rendering underwater work services for Polish drilling platforms and to implement various diving technologies. The technical base created at that time was repeatedly modernised and nowadays it is a cutting edge facility. Over thirty years of experience allows us to assume that the project has a chance to expand the boundaries of knowledge in the field of hyperbaric technologies.

Weaknesses of the project include insufficient repair facilities for the diving gear acquired from the Armed Forces modernisation plan, and an inefficient spare parts supply system.

The most important weakness resulting from the external context is the fact that the supplier provides decompression tables that do not meet all our requirements. The regulations and well-established tradition in the Polish Navy requires that the diving technology used ensures, inter alia, the following:

- $\quad$ in the event of a failure in the oxygen supply, the possibility of completing the decompression using the mixture used during the stay on the bottom,

- $\quad$ in the event of a deteriorating seas state and increasing wave activity, ending the decompression at the stop at $6 \mathrm{mH}_{2} \mathrm{O}$.

The supplied diving technology did not offer any additional recommendations for the treatment of serious cases of decompression sickness resulting from a rapid ascent of a diver or omission of a significant part of decompression stops ${ }^{154}$.

Implementation of independent dives with the use of SCR CRABE SCUBA rebreather gives Poland a chance to meet NATO requirements and increases the possibilities of interoperability of the Polish Navy.

The key cognitive opportunity resulting from the project is the potential to fill a knowledge gap and meet the tactical requirements or develop diving technologies. The acquired knowledge will enable effective actions to be taken in the future. Unfortunately, it should be expected that expensive and long-lasting research should be undertaken at the initial stage of work. With support from the Armed Forces modernisation plan, the chances for the successful completion of the project are very good.

The main challenges are the waiting time for the first results of the project, which always seems too long to the decision-makers, and the high financial resources needed to cover the scientific research. However, the biggest problem is the long-term preservation of the project's results. This problem concerns not only Poland, but almost all partners of the Alliance, because of the generation gap among specialists in hyperbaric technology. In fact, there is a kind of backwardness, which is visible in the repeated solving of the same problems, sometimes with worse results in comparison to the original results.

In the phase of association strength analysis, for the generated strengths $\mathrm{S}$ and weaknesses $\mathrm{W}$, opportunities $\mathrm{O}$, and threats $\mathrm{T}$ for internal and external conditions related to the implementation of the project scope, an analysis was carried out using a three-grade scale:

- 0 no association,

- 1 weak association,

- 2 strong association.

The results are contained in tab. 3 . 
Results of the analysis of the strength of association between strengths $S$ and weaknesses $W$, opportunities $O$ and $T$ threats for internal and external conditions related to the implementation of a domestic diving technology with the use of an independent semi-closed circuit SCR CRABE SCUBA rebreather.

\begin{tabular}{|c|c|c|c|c|c|c|c|}
\hline & & \multicolumn{3}{|c|}{ 0.0pportunities } & \multicolumn{3}{|c|}{ T.Threats } \\
\hline & & 1 & 2 & 3 & 1 & 2 & 3 \\
\hline \multirow{3}{*}{ 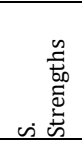 } & 1 & & & 2 & 1 & 1 & 2 \\
\hline & 2 & & & 2 & 2 & 2 & 2 \\
\hline & 3 & 2 & & 2 & 2 & 2 & 1 \\
\hline \multirow{6}{*}{ 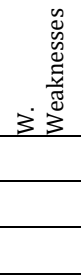 } & 1 & 2 & & 2 & 2 & 2 & \\
\hline & 2 & 2 & 1 & & 2 & 1 & \\
\hline & 3 & 2 & 2 & 2 & 2 & 2 & \\
\hline & \multicolumn{6}{|c|}{ 0-no association oddziaływania } & \\
\hline & \multicolumn{4}{|c|}{ 1-weak association oddziaływania } & & & \\
\hline & \multicolumn{4}{|c|}{ 2-strong association } & & & \\
\hline
\end{tabular}

Results of analysis of implications for strong associations between strengths $\mathrm{S}$ and weaknesses $\mathrm{W}$, opportunities $\mathrm{O}$ and threats $\mathrm{T}$ for internal and external conditions for the implementation of a domestic diving technology using an independent semi-closed circuit SCR CRABE SCUBA rebreather

\begin{tabular}{|c|c|c|c|c|c|c|c|c|c|c|c|c|c|}
\hline & & \multicolumn{3}{|c|}{ O.0pportunities } & \multicolumn{2}{|c|}{ T.Threats } & & \multicolumn{3}{|c|}{ O.Opportunities } & \multicolumn{2}{|c|}{ T.Threats } & \multirow[b]{2}{*}{3} \\
\hline & & 1 & 2 & 3 & 1 & 2 & 3 & 1 & 2 & 3 & 1 & 2 & \\
\hline \multirow{3}{*}{ 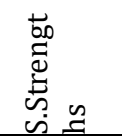 } & 1 & & & $\mathrm{Y}$ & & & $\mathrm{Y}$ & & & $Y$ & & & $\mathrm{Y}$ \\
\hline & 2 & & & $\mathrm{Y}$ & Y & $\mathrm{Y}$ & & & & $\mathrm{Y}$ & & $\mathrm{Y}$ & $\mathrm{Y}$ \\
\hline & 3 & $\mathrm{Y}$ & & $\mathrm{Y}$ & $Y$ & $Y$ & & & & $\mathrm{Y}$ & & & \\
\hline \multirow{7}{*}{ 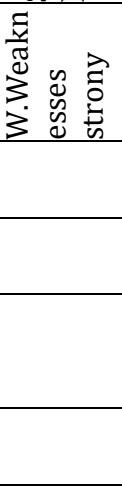 } & 1 & $\mathrm{Y}$ & & & Y & & & & & $\mathrm{Y}$ & $\mathrm{Y}$ & $\mathrm{Y}$ & \\
\hline & 2 & $\mathrm{Y}$ & & & $Y$ & & & & & & $\mathrm{Y}$ & & \\
\hline & 3 & $\mathrm{Y}$ & & & & & & & $\mathrm{Y}$ & & $\mathrm{Y}$ & $\mathrm{Y}$ & \\
\hline & & \multicolumn{6}{|c|}{$\begin{array}{l}\text { - Does a given strength allow to use a } \\
\text { given opportunity? }\end{array}$} & & \multicolumn{5}{|c|}{$\begin{array}{l}\text { Does a given opportunity contribute } \\
\text { to a given strength? }\end{array}$} \\
\hline & & \multicolumn{6}{|c|}{$\begin{array}{l}\text { - Does a given strength mitigate a given } \\
\text { threat? }\end{array}$} & & \multicolumn{5}{|c|}{$\begin{array}{l}\text { Does a given opportunity allow to } \\
\text { mitigate a given weakness? }\end{array}$} \\
\hline & & \multicolumn{6}{|c|}{$\begin{array}{l}\text { - Does a given weakness limit the } \\
\text { possibility of taking advantage of a } \\
\text { given opportunity? }\end{array}$} & & \multicolumn{5}{|c|}{$\begin{array}{l}\text { Does a given threat weaken a given } \\
\text { strength? }\end{array}$} \\
\hline & & \multicolumn{6}{|c|}{$\begin{array}{l}\text { - Does a given weakness increase the } \\
\text { risk associated with a given threat? }\end{array}$} & & \multicolumn{5}{|c|}{$\begin{array}{l}\text { - Does a given threat expose a given } \\
\text { weakness? }\end{array}$} \\
\hline
\end{tabular}

The numbering of generated strengths $\mathrm{S}$, weaknesses $\mathrm{W}$, opportunities $\mathrm{O}$ and threats $\mathrm{T}$ for internal and external conditions concerning the project implementation is identical as in tab. 2 and tab. 3 .

The analysis of implications of the identified strong associations for the left side of tab. 4 was conducted by answering the following questions:

- Does a given strength allow to use a given opportunity?

- Does a given strength mitigate a given threat?

- Does a given weakness limit the possibility of taking advantage of a given opportunity?

- Does a given weakness increase the risk associated with a given threat?

Whereas for the right side of tab. 4 the analysis was carried out by providing answers to the questions:

- Does a given opportunity contribute to a given strength?
- Does a given opportunity allow to mitigate a given weakness?

- Does a given threat weaken a given strength?

- Does a given threat expose a given weakness?

The results of the implication analysis summarised in tab. 4 have the same numbering of strengths $\mathrm{S}$, weaknesses $\mathrm{W}$, opportunities $\mathrm{O}$ and threats T as in tab. 2 and tab. 3.

Only strong associations were described, for which deterministic relations ${ }^{155}$ were revealed in the form of a positive answer to the questions presented in tab. 4 .

Will the existing scientific and research base allow to increase the required operational capabilities within NATO?

After the modernisation, the existing scientific and research base will enable performing tests on measurement stations with the participation of 
experimental divers within the scope of the necessary technologies covering the required operational scenarios. The basic scope of the modernisation of the hyperbaric complex will be the restoration of the cooling capacity of the water in the pool. Modernisation is also required for the system of visual monitoring, diving parameters and recording of conversations. The dive testing station requires building a new metabolic simulator and incorporating it into the system of breathing and hyperbaric simulators.

The existing hyperbaric base also serves as a trainer for MCM divers and is used in the training of MCM divers for higher diving levels.

Will the existing scientific and research capacity allow to increase the required operational capabilities within NATO?

It seems that the Naval Academy still has sufficient human resources to carry out the necessary research. However, medical security is provided by a physician employed under a civil-law contract. The experimental divers are also contracted under civil-law contracts with military units. Therefore, most of the project activities must be carried out outside of business hours. Will the experience gained be sufficient to increase the required operational capabilities within NATO?

It seems that the experience gained in the works on the development of new diving technologies will allow the implementation of the current project. It is expected that new knowledge will be acquired, which will enable a significant increase in work efficiency. Such hopes arise from the development of new mathematical models for the main processes for an ergonomic diver-rebreather system. In particular, an adequate model of respiratory space ventilation would contribute to a significant progression in the design of diving technology and system environment.

Deterministic models should be sought wherever possible while probabilistic models should be used only in the process of validation of the developed technologies.

Will the existing scientific and research base allow to reduce the risk related to difficulties in maintaining the sustainability of project results?

The scientific and research base is an excellent tool for conducting research on new diving technologies. However, in the absence of specialists who would like to undertake research in this area on their own, it will not be possible to maintain the sustainability of the project's results. Similarly as in other world centres, as the scientists working there leave, the competences of these institutions are slowly declining.

Will the existing scientific and research potential allow to mitigate the risk related to the expected long-term implementation of the project?

The impatience of ordering parties is the cause of failure of many projects. Fatal accidents in particular reduce the patience shown to research teams. It seems that the Polish Navy will be able to maintain the necessary patience due to unsatisfactory progress in research into diving technologies for SCR CRABE SCUBA and SCR IS-Mix SCUBA.

At the moment, it appears that the project team has experience in developing new diving technologies. And the procedures and equipment used are at a good worldclass level. This does not guarantee that the risks associated with the expected long duration of the project will be eliminated, but it does provide hope that the project will be successful within the assumed time horizon.

Will the existing research potential reduce the risk related to the expected high expenditures on project implementation?

Unsatisfactory progress in SCR CRABE SCUBA and SCR IS-Mix SCUBA SCR technology research is undoubtedly associated with low budget and time constraints for project teams.

The project budget is typical for projects with an average level of funding. It includes elements of infrastructure modernisation, which is also used for training and practice. Hence, the level of financing did not raise any objections. In the conditions of economic stability of the country, project budgeting seems to be secured.

Will the experience gained be sufficient to mitigate the risks associated with the expected long duration of the project?

The accumulated knowledge base raises great hopes for bridging the knowledge gap in the modelling of ventilation of SCR semi-closed circuit rebreathers. In this area, the key task will be to re-build a metabolic simulator on a new simulation site consisting of a breathing and hyperbaric simulator. The experience gained with the previously used simulator suggests that the project is expected to bring significant progress in knowledge in the design of ergonomic diver-rebreather systems.

Will the experience gained allow to mitigate the risk related to the expected high expenditures on project implementation?

It can be reasonably hoped that during the project implementation a breakthrough will take place and the next knowledge gap will be filled allowing for more effective work on new diving technologies. However, such a scenario usually does not contribute to the reduction of costs, but results in the revaluation of the objectives towards a higher quality standard for the final solution.

If the scientific achievements of the project are significant, it is likely that a higher achievable quality standard will require additional financial support and an extension of the project duration.

Does the insufficient military base limit the possibilities for increasing the required operational capabilities within NATO?

Formally, the insufficient service base for SCR CRABE SCUBA diving equipment does not limit the possibilities to increase the required operational capabilities within NATO, but reduces combat readiness through too lengthy bureaucratic procedures, which can be shortened with goodwill. However, the operation of diving gear is largely based on external services, which have to be contracted under public procurement ${ }^{156}$. This model is not sufficiently efficient in a context where it is necessary to maintain constant, increased combat readiness.

Does the inefficient procurement system limit the possibilities for increasing the required operational capabilities within NATO?

According to the philosophy of conducting combat operations, an inefficient supply system for SCR CRABE SCUBA diving equipment eliminates the possibility of maintaining operational capability to conduct 
underwater combat operations, including those within NATO.

Units dispatching mine patrols should have a separate fund to maintain constant combat readiness. Regardless of the needs, which will be planned on the basis of experience gained and implemented centrally, these units should have at their disposal repair workshops, systems for the production and authorisation of breathing mixes, the ability to promptly purchase gases, spare parts, etc.

Do the current possibilities of the decompression and treatment tables limit the possibilities for increasing the required operational capabilities within NATO?

The project focuses on decompression planning adapted to the operational scenarios implemented by MCM divers, for whom the possibilities of the tables used thus far have been limited in this respect.

In the case of independent deep water dives, it is important to take into account that a diver may make a rapid ascent. The experience of other NATO countries shows that standard procedures based on a set of tables proposed by the US Navy may not be sufficient. Securing such dives may require traditional treatment in saturation conditions. This requires changes in the designs of new decompression chambers planned within the KORMORAN II project, modernised hyperbaric facilities on the PIAST and LECH ships as well as SERCÓWKA kits.

Unfortunately, other NATO countries are not prepared to offer us sufficient support for medical actions, which is why this issue must be resolved with domestic efforts.

Does the insufficient military base increase the risk associated with the expected long duration of project implementation?

Insufficient military service base may cause the lack of operable rebreathers for testing and thus prolong the project implementation time.

Does an inefficient supply system increase the risks associated with the expected long duration of the project?

An inefficient supply system may cause the lack of spare parts for rebreathers and result in the lack of operable devices for testing and thus prolong the project implementation time.

The analysis of the right part of tab. 4 is complementary to the one conducted above and it is unlikely to reveal additional conditions resulting from the project context, hence it will not be presented in this paper.

\section{RISK IN THE PROJECT}

The initial risk analysis for project implementation was performed using the Failure Mode and Effects Analysis (FMEA) method [33]. A different approach will be required for the risk analysis of tactical use of MCM diving technology as an element of the mine warfare system ${ }^{157}$.

Risk analysis, conducted with the FMEA method, is oriented on the capability to predict the occurrence of irregularities in the system or in the process taking place in the system, on the basis of expert knowledge and early development of methods of reaction to the predicted forms of risk materialisation as a threat or opportunity, regardless of the financial scale of the effect of this materialisation. Using the FMEA method, a potential risk may be ranked in terms of probability and technical scale of its impact at the time of its materialisation. The financial scale ${ }^{158}$ of risk materialisation should be assessed in parallel to the technical analysis in order not to focus actions to minimise the financially insignificant effects of risk materialisation, while the more severe ones are left as residual. This method has also been successfully applied in other projects [34-35].

The FMEA methodology not only contributes to minimising the effects of risk materialisation, but also establishes a hierarchy of diagnosed, inherent types of risk and thus allows to determine the necessary level and directions of monitoring of threats and opportunities.

The analysis uses the notions of risk and threat. The differential of the function of risk from the moment $t=0$ to the moment $t$ here defines the threat or opportunity to materialise the risk.

In the initial phase, eight residual possible project risks associated with six types of risk were diagnosed:

1. lack of a sufficient number of experimental divers,

2. lack of control over the hygiene of life of divers,

3. selection of an inadequate population of divers,

4. occurrence of a casuistic $^{159}$ case of decompression sickness DCS,

5. testing of technology in conditions deviating from the actual conditions,

6. inadequate performance of a rebreather. 


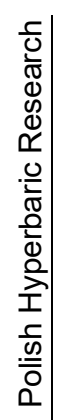

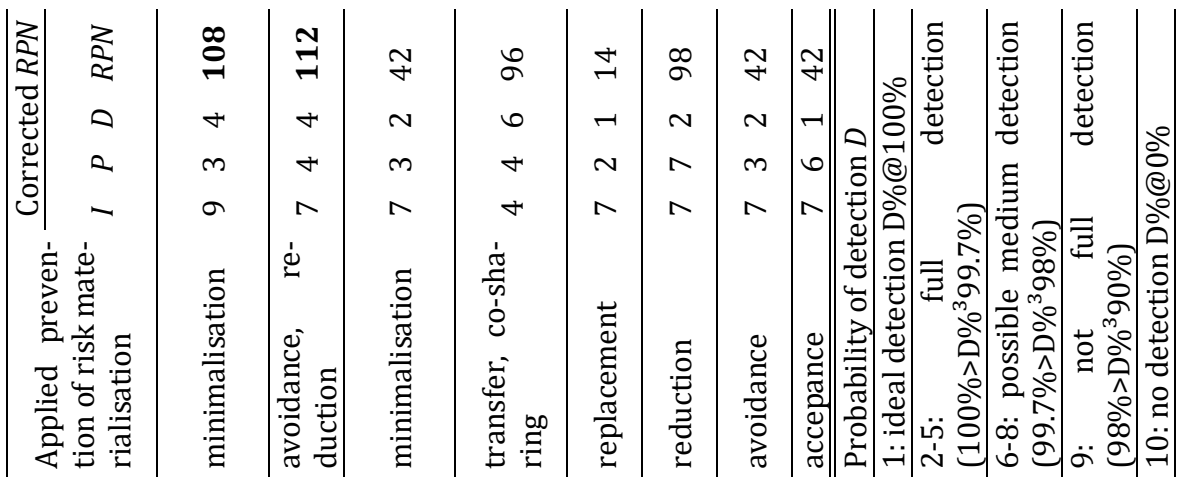

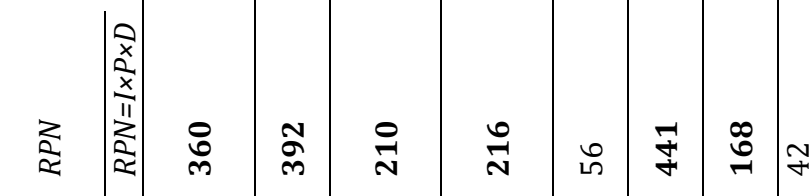

ช่

पू

늠 웜

중.

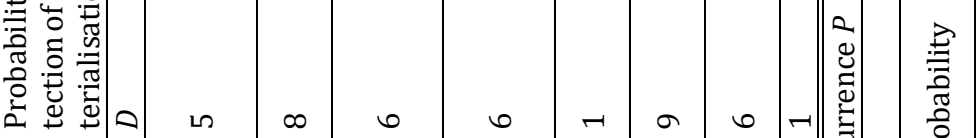

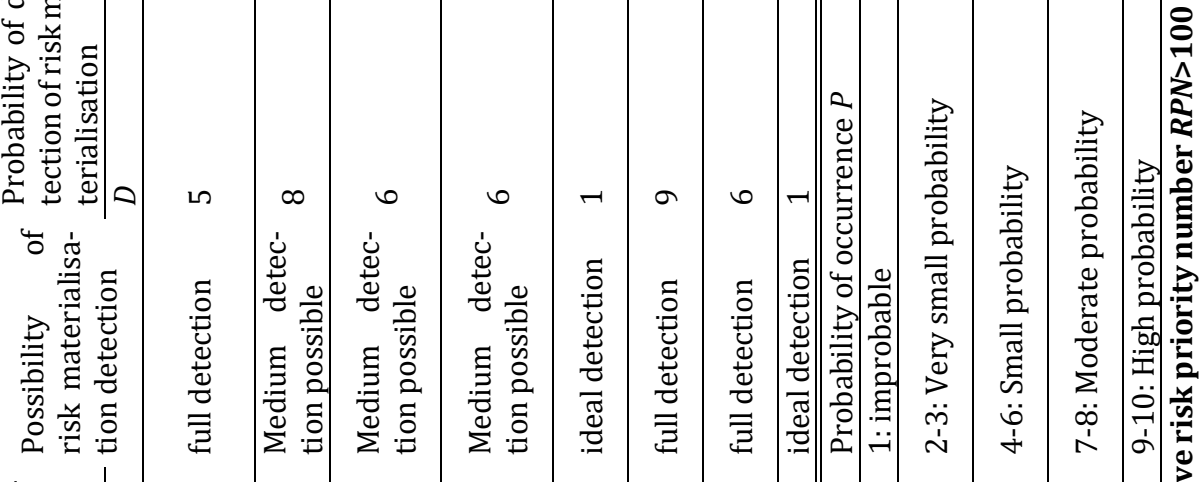
离

$\sim \stackrel{0}{\circ}$

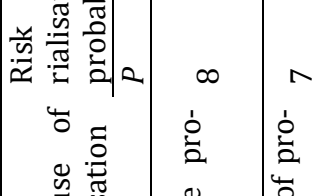

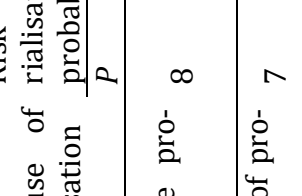

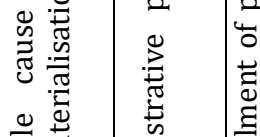

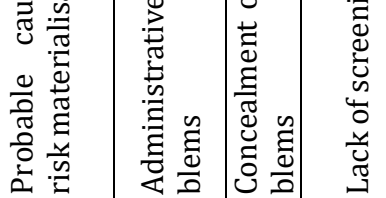

氙

总

若

르응

这

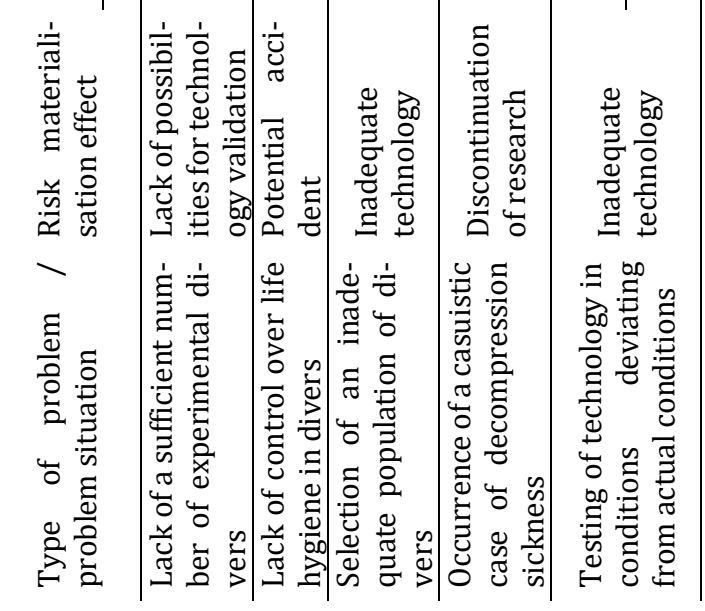

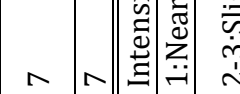

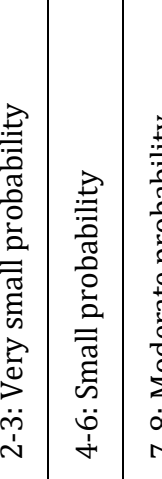


Ad. 1 The intensity of the threat posed by the lack of a sufficient number of experimental divers is high and was determined at a relative level of $\mathrm{I}=8$ in a ten-grade ordinal scale, as the effect of materialisation of this threat will be the inability to validate the proposed technology or validation will be burdened with systematic error. Because of mostly administrative barriers, the probability of the threat being created was estimated at a moderate level and in a relative ten-grade ordinal scale they were determined at $\mathrm{P}=8$ with full detection capability. Therefore, the detection probability was estimated at $100 \%>D \% \geq 99.7 \%$, which corresponds to the relative value of $\mathrm{D}=5$ in the tengrade ordinal scale. The value of the relative number of risk in this case is at the level of $\mathrm{RPN}=320$, exceeding the critical value $\mathrm{RPN}_{\mathrm{kr}}=100$ by more than 3 times - tab. 5 .

As a way of responding to the risk of a lack of an adequate number of experimental divers, which creates the risk of a lack of validation of the technology under development or of validation burdened by systematic error, it was decided to minimise this risk by creating financial incentives and by additionally deciding to conduct experiments outside the working hours of military divers ${ }^{160}$

This reduces the relative probability of materialisation of the risk of bureaucratic barriers to a very unlikely level, estimated at a relative level of $\mathrm{P}=3$, and slightly increases the probability of detection, owing to the expected cooperation with divers, resulting in early notification of inability to participate in the study on a given date: $\mathrm{D}=4$. This allows to reduce the value of the risk number to the level of $\mathrm{RPN}=108$, which falls near the critical value.

To date, no significant problems with the lack of experimental divers have been observed, but the spare time of military divers remains limited, hence the threat does exist. Attempts have been made by the Steering Committee to encourage the owner to request unit commanders to assign divers to the project. This would reduce the likelihood of a threat to the unlikely level of $\mathrm{P}=4$ and the possibility of detection to the level of full detection $D=3$. This would bring the relative number of risks down to the level of RPN=108, slightly above the critical level $\mathrm{RPNkr}=100$, which is identical to the previous one, therefore this option is treated as an emergency option.

Ad.2 Lack of control over divers' life hygiene is a high risk for the project, assessed at I=7 level, because it creates a potential risk of a diving accident at the materialisation of this risk. Such a risk is connected with Ad.1, because the willingness to earn extra income combined with the reluctance to change the behaviour in order to increase the hygiene of life increases this risk. Therefore, the probability of risk materialisation was assessed as moderate, at the level of $\mathrm{P}=7$, with a possible average probability of detection at the level of $D=8$. Lack of control over the life hygiene in divers causes a significant threat to the project at the risk priority number $\mathrm{RPN}=392$. The response to the risk will be to avoid it and reduce it by using diagnostic equipment: a breathalyser and a blood lactic acid testing kit. This will reduce the estimated probability of risk materialisation to small amounting to $\mathrm{P}=4$ and increase the probability of detection to full: $\mathrm{D}=4$ : This will reduce the estimated risk priority number to RPN=112, slightly above the critical value.

Ad. 3 The selection of an inadequate population of divers may be caused by the lack of adequate screenings, but most often results from the need to carry out the project with a limited number of experimental divers available. Hence, the risk is quite closely connected with Ad.1. The intensity of the threat is estimated at a high impact level of $\mathrm{I}=7$. The probability of risk materialisation was assessed at a low level of $\mathrm{P}=5$, with an average probability of detection at a level of $\mathrm{D}=6$. Taken together, this generates the risk priority number of $\mathrm{RPN}=210$, more than double the critical value. The response to the risk will be to minimise it by conducting thorough tests on divers during experiments. This will minimise the probability of risk materialisation to a very low $\mathrm{P}=3$ and increase the probability of detection to full, i.e. $\mathrm{D}=2$. This reduces the risk priority number to the negligibly small $\mathrm{RPN}=42$. During the previous projects one of the divers was diagnosed as not meeting the requirements of the model of operation of the rebreather. It seems that in the future it will be necessary to use screening tests for divers belonging to the group eligible for training and diving with the use of SCR CRABE SCUBA.

The available population of military experimental divers is not entirely adequate because, in accordance with the applicable law, it is permissible to admit soldiers who are qualified as senior divers to work as experimental divers. The path to obtaining such qualifications is long, hence they are older individuals in the population of divers who will use the developed technology. One of the ways to maintain the adequacy of the approach used is to invalidate the unrealistic requirement to use the technology only by soldiers with privileges of senior mine divers.

Ad. 4 A casuistic case of decompression sickness DCS, or DCS with a rare course or incidence, can always disrupt the validation process. Some of the conditions conducive to the occurrence of a case-specific DCS are listed in the part discussing the physiological context ${ }^{161}$. Partial countermeasures include testing of blood acidification or the presence of alcohol in the exhaled air, control of divers' life hygiene, training, etc. However, bad psychological attitude, taking diet supplements, sleep disorders, etc., may be dissimulated, concealed or ignored by a diver and not diagnosed during a medical interview. The materialisation of such risks is particularly acute, as it can lead to the retention of studies for the time of a postaccident investigation. The intensity of the hazard has been estimated to be high and amount to $\mathrm{I}=7$. The probability of risk materialisation is unlikely and reaches $\mathrm{P}=4$. The probability of pre-diving detection can be estimated as average: $\mathrm{D}=6$. The risk response strategy is to make divers aware of the risk and to transfer it and share it with the insurer, hence significant resources have been allocated for the insurance of experimental diving under civil liability insurance. This will reduce the risk impact intensity to a level of $I=4$. This in turn will reduce the risk priority number from $\mathrm{RPN}=216$ to $\mathrm{RPN}=96$, which is slightly below the critical value.

Because the occurrence of a casuistic case of decompression sickness DCS is always possible, protection against DCS symptoms in divers is provided by monitoring the free gas phase in venous vessels. The method used at the academy for years has proven to be extremely useful.

Ad.5 Checking the technology, in conditions different from the actual conditions, creates a high intensity of risk materialisation, assessed at $\mathrm{I}=7$. Two cases of risk materialisation are probable.

With a limited possibility to modify the water 
temperature, the probability of risk materialisation was assessed as average at $\mathrm{P}=8$, with ideal detection $\mathrm{D}=1$. The risk priority number in this case is below the critical value of $\mathrm{RPN}=56$. The reaction to this risk is its conversion into an opportunity by building a water cooling system in the pool of the hyperbaric complex. In this case, the estimated probability of risk materialisation with later use of the technology decreases to a relative value of $\mathrm{P}=2$ corresponding to a very unlikely occurrence. Thus, the risk priority number drops to a negligibly low level of RPN=14.

The second type of threat is associated with an excessive error in the determination of the content of oxygen and other gases in the premix ${ }^{162}$. It would seem to be a very unlikely occurrence, but such cases had been observed in previous projects, hence the probability has been estimated at a moderate level of $\mathrm{P}=7$. Such errors arise even with a small deviation from the established SOP procedures 163 , good diving practice GLP164 or ergonomic incompatibility between an operator analyst-a measuring instrument. In routine tests, such a risk can often easily materialise. The probability of risk materialisation detection is not full $\mathrm{D}=9$. This produces a high technical threat, as the risk priority number is more than four times the critical value of RPN=441. The strategy for responding to the risk is to reduce the risk through: separation of an experienced observer in whose presence the analyses will be performed, commissioning the analyses to two laboratories or performing additional checks in an external laboratory. This will increase the probability of detection to full $\mathrm{D}=2$ and reduce the risk priority number to a value slightly below the critical value, i.e. $\mathrm{RPN}=98$.

Deviations from the assumptions for earlier diving technologies with the use of Nx/Tx-SCR CRABE SCUBA were diagnosed, consisting in the expense of greater than expected effort during the phase of entering and leaving the water. Divers descend from on board the ship and not from a pontoon, undertaking strenuous effort while moving on the gangway. As a countermeasure, it is proposed that the level of technology readiness be raised from level VIII to level IX by the research team, thus taking steps towards continuation of the project while taking into account these conditions. The materialisation of such a risk is critical as it depletes the project of significant financial resources as well as the time spent on project implementation. Such accidents do happen, therefore it is worthwhile to use the Lessons Learned guidebook made available by the NATO Navies.

In the case of not yet fully tested SCR CRABE SCUBA, the risk of inadequate operation may be caused by two reasons: lack of a thorough check before diving or failure. In both cases, the materialisation of risk may lead to a diving accident, hence the intensity of the hazard impact has been assessed to be high, i.e. $I=7$. The probability of improper testing of the rebreather prior to diving was estimated at the level of $\mathrm{P}=5$ and the probability of detection at the level of $\mathrm{D}=7$ as a result of an occurrence of a case of improper preparation of the rebreather during the research owing to a deviation from SOP. These parameters generate the risk priority number at $\mathrm{RPN}=24$. The strategy of reaction to risk will consist in its minimisation by permanent, qualified supervision. Therefore, an extended supervision team will be used to conduct experiments by qualified and experienced specialists from the Academy. This will allow to reduce the level of probability of materialisation of the risk of a potential diving accident to the level of $\mathrm{P}=4$ and the probability of detection to $\mathrm{D}=3$. The reaction to the risk caused a reduction in the risk priority number to the acceptable level of RPN=84.

An inadequate operation of the diving apparatus is always likely. Preventing this risk is based on cooperation with the manufacturer through an industrial partner in the scope of changes in the design of the device to prevent the occurrence of irregularities in operation and bilateral scientific cooperation with CEPHISMER Tulon in the field of monitoring of existing problems in the French Navy.

Based on the analysis of the experimental dives conducted to date, the probability of failure of the diving apparatus was estimated at a low level: $\mathrm{P}=6$, whereas the probability of detecting a failure at the ideal detection level $\mathrm{D}=1$. Hence the risk priority number is at the small level $\mathrm{RPN}=42$. The response to the risk is its acceptance.

The presented analyses show that after applying the reaction to the analysed risks, the value of the risk priority number decreased. The intensity ${ }^{165}$ for certain risks in the project has been slightly reduced. The residual risk is still high, so the project should be classified as potentially posing a high technical and medical risk.

\section{SUMMARY}

Due to specific military requirements, diving technologies should be knowledge-based as extensively as possible. The planned research cycle will be based on a country based approach favouring deterministic modelling of semi-closed systems as a part of the SCR CRABE SCUBA rebreather. The issues of respiratory ventilation of the SCR CRABE SCUBA with both a premix and oxygen are key issues for the project and are therefore the main focus of the research. The system was developed using a process-oriented approach and system engineering methods. Under national conditions, the validation of the accepted theories by methods of inference based on binominal distribution is not possible to implement, hence the inference is based on sequential analysis [23].

The project is related to the MCM diving technology realised in a wide range of depths, as an element of the mine-warfare system. The dives should be conducted from the surface to about $80 \mathrm{mH} 20$ and to cover different depth ranges decompression will be performed with oxygen and various Nitrox mixtures to the depth of 50 $\mathrm{mH} 2 \mathrm{O}$, whereas at greater depths with helium-based mixtures166. In principle, decompression should be accelerated by the use of oxygen. The context of utilisation of diving technologies as elements of the minefighting system seems to be particularly important. The goal should be to ensure that the conservatism of technology poses a threat within the limits ${ }^{167}(1 ; 3) \%$ of an occurrence of DCI, as estimated for an epidemiological risk. The project did not include any studies on the possibility of undertaking repeated or repetitive dives.

During the project implementation, attention will be paid to selected problems of divers' life and work hygiene and adaptation training. The developed SOP procedures resulting from previous works and regulations will be maintained and, if necessary, revised.

The task of the project is to develop technologies for point diving. This approach requires both the development of a diving technology taking into account the lack of performing of additional work by the diver, where the main problem is the risk of the occurrence of symptoms of central oxygen toxicity CNSyn, as well as 
dives performed during emergency situations, posing a potential threat of developing symptoms of decompression sickness DCS.

The tradition cultivated in the Polish Navy has shown that the decompression system should be secured with a system enabling the decompression process to be carried out in difficult conditions. Said system should consist of hyperbaric procedures and contain the required technical and medical equipment to execute them, including procedures to evacuate the diver to a specialist hyperbaric facility or hospital. Elements of the system of securing the realisation of therapeutic processes may be borrowed or developed anew. The system of therapeutic recompression tables should provide for therapeutic procedures in the event of a diver's rapid ascent from significant depths, omitting decompression stations.

The use of diving apparatus with semi-closed circulation of the breathing mix and mixtures with increased oxygen content requires the development of a recruitment process for divers and maintaining them in proper condition. The risk of developing symptoms of decompression sickness and central oxygen toxicity is higher than for recreational divers.

An important parameter of a diving operation is the possibility of burdening the diver with work, which is connected with the process of ventilation of the breathing space of the device, as well as the process of decompression and the increasing risk of central oxygen toxicity

Regardless of the time and depth of the transition to oxygen decompression, an effective procedure should be sought for the process of flushing the breathing space of the diving device with oxygen. The decompression acceleration algorithm will depend directly on its effectiveness. Of course, it is necessary to consider the possibility of switching from oxygen decompression to gas mixture decompression at any time.

The system for conducting underwater works may not provide the possibility of repetitive dives, but it should normalise the amount of time spent on rest required to conduct a second dive.

Predefining the algorithm for maintaining a constant, assumed composition of the breathing mix inhaled by the diver through the diving apparatus requires making assumptions about the individual parameters of the diver, which are not always met, hence divers should be examined in terms of compliance. The individual parameters of a diver change with the age of the diver and the degree of preparation/training. It appears good practice to check the key safety parameters of a diver at the time of each training course for higher diving qualifications.

In the process of diving safety analysis in the Navy of the Republic of Poland, it is crucial to properly prepare a diver in terms of fitness and efficiency, as well as for the decompression, because the individual parameters of a diver tend to fluctuate significantly as a result of adaptation training or its discontinuation. Control of individual parameters of a diver is possible during obligatory training sessions carried out with the use of hyperbaric simulators, preferably hyperbaric swimming simulators or simulators of underwater work ${ }^{168}$, as part of the prevention of potentially dangerous situations.

\section{Conclusions}

The scientific approach is based on a thorough analysis of the processes taking place in the examined system in order to be able to forecast its future ${ }^{169}$ with satisfactory reliability 170 .

The project uses a process-based approach to developing the theory that provides the possibility to plan underwater activities. The reliable ${ }^{171}$ deterministic model for the ergonomic man-machine system established in the project offers the possibility of prediction 172 of the required reliability. The described process of deterministic modelling by its nature enables continuous improvement of prediction precision and estimation of threat level, while diagnosing deviations from model repeatability or precision. This is important because, due to specific requirements, military diving technologies should be as knowledge-based as possible.

\section{FINAL INFORMATION}

This paper contains only an extract from the performed context analysis for the project, without the description of the project assumptions, selection and analysis of critical parameters $\mathrm{CTQ}^{173}$ and the identification of the main research process, which constitutes the introduction to the base project implementation plan and communication procedure, which on the other hand are the basis for the preparation of the feasibility study of the project. As can be seen, the context analysis explaining the needs and conditions of the project implementation is quite extensive and complex, even for the project stakeholders. The decision to publish it was connected with providing answers to questions challenging the purpose of undertaking the project. Project documents were assessed on a multi-level basis by various institutions, including independent scientific experts. Opinions calling into question the legitimacy of a decision to launch a project undermine their authority. Most of the decision-makers are unknown to me, but as a project manager, it is my duty to protect the results of their work. I hope that the positions negating the decisions made resulted only from the lack of awareness of how deep and accurate the thought process underlying the decision was. Information about the project is, in its nature, public information and all institutions and persons possessing knowledge about it are obliged to answer the questions asked. The prepared application for the project is a legally protected good in Poland, hence the best way to reveal it is a scientific publication by the author. Therefore, should there still be a need for further explanations, the only obstacle to further disclosure of the assumptions for the project is the approval of a magazine printing such extensive material. 


\section{REFERENCES}

1. Abysmal Diving Inc. 2001. Advanced Dive Planning Software. [CD] 6595 Odell Place, Suite G. Boulder Colorado, 80301 : Abysmal Diving Inc., 2001. ABYSS-2000 v.2.30.17

2. Bennett P.B., Elliott D.H. 1975. The physiology and medicine of diving. London : W.B. Saunders Company Ltd., 1975. ISBN 0-7020-0538-X;

3. Brubakk A.O., Neuman T.S. 2003. Bennett and Elliott's physiology and medicine of diving. brak miejsca : Saunders, 2003. ISBN 0-7020-2571-2; Bühlmann A.A. 1984. Decompression-Decompression sickness. Berlin : Springer-Verlag, 1984. ISBN 3-540-13308-9; ISBN 0-387-13308-9; Donald K. 1992. Oxygen and the diver. Harley Swan : The SPA Ltd., 1992. ISBN 1-85421-176-5;

Donald K.W. 1947. Oxygen poisoning in man part I. British Medical Journal. May 17, 1947, pp. 667-672;

7. Frånberg O. 2015. Oxygen content in semi-closed rebreathing apparatuses for underwater use: Measurements and modeling. Stockholm : School of Technology and Health, 2015. ISSN 1653-3836.

8. Gerth W.A. 2002. Overview of survival functions and methodoology . [aut. książki] Weathersby P.K. Gerth W.A. Survival analysis and maximum likelihood techniques as applied to physiological modeling. Kesington : Undersea and Hyperbaric Medical Society Inc., 2002;

9. Harabin A.L. 1993. Human central nervous system oxygen toxicity data from 1945 to 1986. Bethesda : Naval Medical Research Institute, 1993. NMRI 93-03; AD-A268-225.

10. Huggins K.E. 1992. The dynamics of decompression workbook. Ann Arbor : The University of Michigan, 1992.

11. Kłos I. i Kłos R. 2004. Polish Soda Lime in military applications. Oświęcim : Chemical Company DWORY S.A., 2004. ISBN 83-920272-0-5.

12. Kłos R. 2000. Rebreathers with breathing mix regeneration. Poznań : COOPgraf, 2000. ISBN 83-909187-2-2.

13. - 2019. Designing of diving technologies - process approach. Polish Hyperbaric Research. 2019, Vol. 66, 1, pp. 7-24

14. - 2013. Risk diagnosis on the example of a technical university. Logistyka. November-December, 2013, 6, pp. CD1: 275-294.

15. - 2014. Inherent unsaturation. The risk of central nervous system oxygen toxicity part 1. Polish Hyperbaric Research. 1, 2014, Vol. 46, DOI: HTTP://DX.DOI.ORG/10.13006/PHR, pp. $37-64$.

16. - . 2015. Catalytic hydrogen combustion on a sumbarine. Gdynia : Polskie Towarzystwo Medycyny i Techniki Hiperbarycznej, 2015. ISBN 97883-938-322-3-1.

17. - 2007. Modeling of ventilation processes of normo- and hyperbaric facilities. Gdynia : Akademia Marynarki Wojennej, 2007. Postdoctoral thesis PL ISSN 0860-889X no. 160A.

18. - 2011. Possibilities of decompression selection for CRABE diving apparatus - assumptions for standard and experimental dives. Gdynia : Polskie Towarzystwo Medycyny i Techniki Hiperbarycznej, 2011. ISBN 978-83-924989-4-0.

19. - 2012. Possibilities of adaptation of oxygen-nitrox exposures for AMPHORA type diving apparatus - assumptions for standard and experimental dives. Gdynia : Polskie Towarzystwo Medycyny i Techniki Hiperbarycznej, 2012. ISBN 978-83-924989-8-8.

20. - 2017. Pollutions of the hyperbaric breathing atmosphere. Scientific Journal of Polish Naval Academy. 2017, Vol. 208, DOI: 10.5604/0860889X.1237621, pp. 31-44.

21. - 2018. Securing the hyperbaric treatment of decompression sickness in the Polish Navy. Polish Hyperbaric Research ISSN 1734-7009; e-ISSN 2084-0535. 2018, Vol. 65, 4, pp. 7-23. Polish-English Bilingual Publication.

22. - 2014. Survival analysis. The risk of central oxygen toxicity part 3. Polish Hyperbaric Research. 3, 2014, Vol. 48, DOI: HTTP://DX.DOI.ORG/10.13006/PHR.48.3, pp. $33-48$.

23. - 2016. Trimix decompression system for CRABE diving apparatusGdynia : Polskie Towarzystwo Medycyny i Techniki Hiperbarycznej, 2016. ISBN 978-83-938322-5-5

24. - 2013. Oxygen tolerance test. Polish Hyperbaric Research. 2013, Vol. 45, 4, pp. 69-78.

25. - 2014. The hazard of central oxygen toxicity occurrence. The risk of central oxygen toxicity part 4. Polish Hyperbaric Research. 4, 2014, Vol. 49, DOI: HTTP://DX.DOI.ORG/10.13006/PHR.49.2, pp. $19-31$

26. - 2014. The he pathophysiology related to the toxic effect of oxygen. the hazard of central oxygen toxicity part 2. Polish Hyperbaric Research. 2014, Vol. 47, HTTP://DX.DOI.ORG/10.13006/PHR.47.2, pp. 15-34.

27. - 2007. The use of statistical methods in diving technique - Skrypt. Gdynia : Polskie Towarzystwo Medycyny i Techniki Hiperbarycznej, 2007. ISBN 978-83-924989-26.

28. Kłos, R. 2009. Soda lime in military applications. Gdynia : no name, 2009. ISBN 978-83-924989-5-7.

29. Lambertsen C.J. 1986. Studies in isobaric counterdiffusion. Philadelphia : Institute for Environmental Medicine, 1986.

30. NOAA. 2017. NOAA diving manual - diving for science and technology. [ed.] Administration National Oceanic and Atmospheric. VI. Flagstaff : Best Publishing Co., 2017. ISBN 9781930536883.

31. PN-EN 60812:2009. 2009. Failure modes and effects analysis techniques (FMEA). Warsaw : Polski Komitet Normalizacyjny, 2009. ICS 03.120.01; $03.120 .30 ; 21.020$

32. PN-EN-14143. 2005. Diving equipment. Self-contained closed-circuit diving apparatuses. Warsaw : Polski Komitet Normalizacyjny, 2005. ICS 13.340.30; 97.220 .40

33. Predictive studies IV. 1978. Work capability and physiological effects in He-O2 excursions to pressures of 400-800-1200-1600 fsw. Philadelphia : Institute for Environmental Medicine University of Pennsylvania, 1978. Report 78-1.

34. Report of proceedings Technical Symposium on The human factor in North Sea operational diving:. Proceedings Technical Symposium on The human factor in North Sea. 4-5 Nov1976. Heathrow : Hotel London, 4-5 Nov1976.

35. Shykoff B. 2007. Performance of various models in predicting vital capacity changes caused by breathing high oxygen partial pressures. Panama City : Navy Experimental Diving Unit, 2007. NEDU Report TR 07-13.

36. von Ahsen A. 2008. Cost-oriented failure mode and effects analysis. International Journal of Quality \& Reliability Management 25: 2008 . 2008, Tom 25, DOI: 10.1108/02656710810873871, pp. 466-476.

37. Wald A. 1947. Sequential Analysis. New York : Jon Willey \& Sons, Inc., 1947.

dr hab. inż. Ryszard Kłos, prof. nadzw.

AMW Akademia Marynarki Wojennej im. Bohaterów Westerplatte

Zakład Technologii Prac Podwodnych

81 - 103 Gdynia 3

ul. Śmidowicza 69

Tel: +586262746

ORCID identifier No: 0000-0002-4050-3978

\footnotetext{
${ }^{1}$ methodology is a collection of principles concerning the performance of selected processes,

2 Semi-Closed Rebreather Self-Contained Underwater Breathing Apparatus,

3 technology is understood here as system optimisation for a given process,

${ }^{4}$ unless requests are made for their more precise interpretation,

${ }^{5}$ resulting from tactics,
} 
${ }^{6}$ by way of various analyses, including studies of feasibility, competitiveness or risk analysis,

${ }^{7}$ system where more than the necessary elements have been applied due to functional reasons for the purpose of increasing its reliability,

8 although it does not have to happen,

${ }^{9}$ Mine CounterMeasure,

10 i.e. with little risk of an occurrence of even mild symptoms of DCS (DeCompression Sickness),

11 slower for the decompression process,

${ }_{12}^{12}$ polish literature refers to such a procedure as extended decompression,

${ }^{13}$ conservatism will amount to $100 \%$ for the gradient equal to $30 \%$ of the maximum saturation value and $0 \%$ for $70 \%$ of the value of this gradient,

${ }_{14}$ Decompression Illness, as a term broader than DCS, for instance by including CNSyn (Central Nervous Syndrome),

15 improving the mobility of disabled persons,

${ }^{16}$ enabling people with disabilities to participate in life, social and sporting activities, at a level similar to that of others with similar disabilities; for example, diving for people lacking limbs or diabetics' diving clubs,

17 for example, failure of a hoist, winch, underwater vehicle, explosion, displacement of a wreck or its component, etc.,

18 this situation occurs when a diver is rescued by their safety diver during any type of diving,

${ }^{19}$ Explosive Ordinance Disposal

20 Special Response Team,

21 this applies to operations in peaceful conditions in the fight against terrorism, but when taking asymmetric actions by the opponent, an appetite for risk may reach much higher values,

${ }^{22}$ some countries use procedures for assessing and selecting threats according to their tactical situation assessments,

${ }^{23}$ during an emergency to a depth of $60 \mathrm{mH}_{2} \mathrm{O}$,

24 the application of neon also seems possible,

25 above $1 \%$ but not more than $3 \%$,

${ }^{26}$ Decompression Sickness,

27 because the most common way to intensify decompression is to use possibly high oxygen partial pressures,

${ }^{28}$ for example, rest time before diving or undisturbed sleep in the night before diving,

29 irrespective of the time of stay at it,

${ }^{30}$ an interesting solution could be the use of Neox,

31 for instance, when entering a diving bell,

32 Human Factors,

${ }^{33}$ Ventilatory Equivalent for Oxygen,

34 in the sense of physical or mental phenomena subject to experimental cognition,

35 the divers were conventionally classified as "delicate" and "resistant" to the conditions of strenuous decompression,

${ }^{36}$ current attitude to diving,

${ }^{37}$ resistance to panic, melancholy, depression or resignation is not comparable to the ability to soberly assess the situation, make clear use of the knowledge resources and take effective action under stressful conditions,

38 eyes are 'the mirror of the soul',

${ }^{39}$ muscle tension or tremor can be checked in passing while checking the equipment by touching the diver's muscles or placing a hand on his/her shoulder,

41 not only heart rate but also pulse volume,

42 verifying that the diver remembers and has easy access to valves, switches, watch, panel, knife, etc.,

${ }^{43}$ decompression does not end with reaching the surface, but a state of equilibrium with the respiratory atmosphere is achieved through slow isobaric decompression, after saturated dives the process is the longest,

44 up to one hour after completing previous decompression,

45 more than one hour from the completion of previous decompression,

46 clearance time,

47 it does not have to be an air atmosphere, because the diver can breathe on the surface, for example from an oxygen inhaler,

48 it ensures, for instance, being able to reach for a mouthpiece that has escaped from the mouth, access to valves, possibly floating lines, vegetation that may entangle the diver, etc.,

49 in water bodies the temperature in the water layers can stratify, in the thermocline the temperature changes quickly with a change in depth,

50 for example, during transport activities or when resting on the beach,

51 Standard Operating Procedures,

52 vasoconstriction,

${ }^{53} 6.0 \mathrm{~N}$ oxygen is on the market, which means $99.9999 \%$ oxygen in the gas,

54 although, in this case too, the content of impurities increases with the increase in 'dead spaces',

55 washout period,

${ }^{56}$ washing of the breathing space of the diving apparatus while at the bottom is undesirable due to the direct proximity of a mine or diver detection and combating systems,

${ }^{57}$ for example, it is easier for a diver to double the predicted time of oxygen decompression and to complete it with the use of an operational mixture in the event of a failure of oxygen supply than to calculate this time according to a different formula,

59 the diver omits a part of the decompression and, after the ascent and a limited time on the surface, is compressed again and subject to further decompression in the decompression chamber,

60 thus making it more conservative,

61 artificial extension of stay time at the bottom,

62 this technology variant takes into account stressful situation such as when a diver has for example to operate in sea currents,

63 Treatment Tables,

${ }^{64}$ such as passing the oxygen tolerance test,

65 in the case of recreational dives the risk is usually specified at the level $p=1 \%$ and for combat dives at $p \leq 5 \%$ with significance $\alpha=0.01$,

66 outside the saturation zone expending more effort is dangerous,

67 rest will be necessary for the performance of mine work or caused by tactical situation connected with the need to reduce noise emission, but in such

a case the problem of an increased risk of central oxygen toxicity should be considered,

68 for example, with an open circuit of the breathing mix,

69 for example, in the form of additional devices taken by a diver or suspended in the water depths,

70 many additional elements of the system can be added, such as a communication subsystem increasing mental comfort, having a significant impact on decompression processes,

71 speeding up,

72 for instance, in the case of oxygen supply failure,

73 additional rebreathers suspended in water or carried by a diver,

74 according to Canadian practice, but in Poland an interval of up to 5 minutes was allowed,

75 in such a case there is a much greater certainty that the diver will reach the decompression chamber on time,

${ }^{76}$ such designs are common for cable-supplied breathing systems, such as Polycom 101 manufactured by Drägerwerk AG Lübeck,

77 for example, exposure to nitrogen narcosis,

${ }^{78}$ for example, during descent and staying at the bottom, Trimix will be used and in the decompression process it will be replaced with Nitrox and later with oxygen,

79 the partial pressures of gas components of the breathing mix $\left(\mathrm{p}_{1} . . \mathrm{p}_{\mathrm{j}}, \mathrm{p}_{\mathrm{i}}\right)$ do not always have to change smoothly with a change in the depth $\mathrm{H}$, because a rebreather can implement an algorithm to maintain a constant partial pressure of a given gas through an adapted change in its content during a change in pressure, such as devices achieving a constant partial pressure of oxygen $p_{i}\left(p \_1 . . p \_, p \_i\right):$ Mk15/16,

80 this does not apply to dives from the saturation plateau,

81 the supply of oxygen can also be achieved by delivering it to the circuit together with other components of the breathing mix,

82 for example, flinching during a panic attack, 
83 an actuating element of an automation system that performs a predefined process of reaction to forced action,

84 often under electronic control,

85 decrease of respiratory action in trained athletes in relation to the average,

${ }^{86}$ heart rate decrease in trained athletes in relation to average; this effect is amplified in the case of immersion in water (as opposed to immersion in virtual environments, art or culture),

87 what is meant here is not diving training, but adaptive training for other activities

88 in real-life conditions, such verification has thus far been difficult to implement,

89 the technology should have a declared appetite for risk that directly results from the tactical context,

$9^{90}$ External/Auxiliary Breathing System, emergency breathing system: "pony", etc.,

${ }^{91}$ due to thermal protection preventing cooling and overheating and thus influencing the risk of central oxygen toxicity CNSyn,

${ }^{92}$ analysers of oxygen partial pressure / composition and carbon dioxide content were developed as optional equipment for the SCR CRABE SCUBA rebreather,

93 the theory and practice of using equipment and instruments to achieve the intended purpose,

${ }_{94}$ Mine Countermeasure,

${ }_{95}$ Explosive Ordnance Disposal,

${ }^{96}$ Improvised Explosive Device Disposal,

97 Mine Countermeasures Vessel,

${ }^{98}$ Autonomous Underwater Vehicle,

99 Unmanned Undersea Vehicles,

100 Remotely Operated Underwater Vehicle,

101 i.e. a reconnaissance vehicle operating from the vessel,

102 Autonomous Surface Vehicle,

${ }_{103}$ Network Centric Warfare,

${ }^{104}$ MCMV usually need shielding ensured by other classes of ships and aircraft,

${ }_{105}$ MCM divers can, for example, be used to: to release entangled MCMV equipment, to prepare to extract exercise torpedoes fired by submarines, to harvest or destroy undetonated self-propelled or dropped explosive devices, etc.,

106 also secretly, for example, by submarines,

107 for instance, of the infrastructure securing against reconnaissance or landing operations,

108 Unexploded Ordnance,

109 diving technology for such activities should differ from typical military and training technology,

110 e.g. by rapid pulling back by a fast boat, blowing out with a blow directed from a special cannon, etc.,

111 for example, underwater air curtains or water sleeves, lining with rubber, shock wave damping plastic, used on land,

112 activities involving the destruction of electronics or the jamming of internal and external signals,

113 wooden plastic pegs, lead bullets, water stream, etc.,

${ }^{114}$ Explosively Formed Penetrator,

${ }^{115}$ Assuming, as an alternative variant of the operation, a strike with the introduction in the first line of units capable of launching elongated charges and burning the access routes or blocking the passageways by air or rocket force strike in order to burn the crossing. However, the impact exposes the operation to the necessity of undertaking a combat for which the opponent may be prepared. Opponent forces are able to detect and counteract attack line forces or aerial attacks. In addition, it is not possible to maintain secrecy until the landing has taken place. In addition, if significant losses are incurred, then despite a successful breakthrough, occupying the defended area or conducting a pursuit may not have a chance of success. Consideration of using SRT or MCM troops to secretly identify and mine obstacles, despite about $100 \%$ of the risk associated with the lack of possibility to recover the subdivision of divers, if there is a probability of completing the task with $70 \%$ confidence at $95 \%$ confidence level it seems justified from the point of view of economics of conducting combat operations, provided that the possible detection of underwater activity can be immediately compensated by the implementation of the breakthrough variant,

116 Very Shallow Water,

117 for instance, in the form of a floating ring,

118 for example, having the ability to move or bury,

119 approximately 35 years ago,

120 the use of statistical models was reserved only for the validation process,

121 it was difficult to choose such a tactic, as it is widely held that it is impossible to develop sufficiently accurate and reliable deterministic models for such a complex human-machine interaction system as is the case with diving,

122 a typical analytical approach was applied, which requires a synthesis of the developed models and validation with the use of a statistical model

${ }^{123}$ most often related to the volume of ventilated space,

$124 \varepsilon$-breathing module is the ratio of oxygen consumption to lung ventilation $\varepsilon(\mathrm{H})=\dot{\mathrm{v}} / \dot{\mathrm{V}}_{\mathrm{E}}$ related to diving depth $\mathrm{H}$,

125 at least several may be recommended: neo-haldanian, RGBM, VPM etc.,

126 the ratio of consumed oxygen stream $\dot{v}$ to ventilation stream $\dot{\mathrm{V}}_{\mathrm{E}}: \varepsilon=\frac{\dot{\mathrm{V}}}{\dot{\mathrm{V}}_{\mathrm{E}}}$,

127 repeatability and reproducibility with assumed accuracy at the assumed significance level,

128 similar, for instance, to the role of ventilated volume in the ventilation model for a submarine [14],

129 the representativeness of the group is limited to divers meeting the criteria for military divers and those who can perform the role of experimental divers,

130 in relation to oxygen content in the premix supplied into the breathing space,

131 for stabilised respiratory parameters of a diver,

132 biodiversity,

133 Human Factors,

134 for anaerobic organisms it is a lethal toxic agent,

135 symptoms similar to lung burning with chemicals

136 in relation to central nervous system,

137 reduced red blood cell count, decreased vital lung capacity, oxygen induced blindness, etc.,

138 Central Nervous Syndrome,

139 this theory forms the basis for epidemiological research, research into

mortality and biodiversity, machine reliability, risk analysis, etc.

140 a return to the state preceding the oxygen exposure, consisting in deactivation of potentially dangerous reactive oxygen compounds by biochemical mechanisms as a result of exposure to high partial pressures of oxygen,

141 commonly used in computer programmes for planning civil technical dives [36]

142 considered dangerous to a wide range of divers,

${ }_{143}$ possibility of performing decompression at the last station at the depth of $6 \mathrm{mH}_{2} \mathrm{O}$, possibility of omission of oxygen decompression, possibility of additional effort load, taking into account previous dives, taking into account the type of transport, taking into account low temperature dives, etc.,

144 such deviations occur when a diver has a significantly developed muscle tissue compared to typical, for this reason one diver was rejected,

145 Treatment Tables,

146 as military dives are carried out in pairs,

147 reproducibility and repeatability,

148 for example, in the diver's physical preparation, reduction of the effectiveness of flushing the respiratory space of the rebreather, inappropriate preparation of breathing mixes or deterioration of their required quality, inappropriate packing of the scrubber or reduction of its quality parameters, etc.,

149 the occurrence of rare medical conditions or diseases,

150 most of the elements of the system allowing for the implementation of the project constitute the laboratory base of the Naval Academy described below,

151 implementation of domestic diving technology was due to the lack of certain procedures required by tradition and national law which is not in place for diving technology supplied with the rebreather, as referred to below,

152 Strengths, Weaknesses, Opportunities, Threats,

${ }^{153}$ CPBR 9.5 implementation objective 31 technical, medical and legal problems of human long-term presence under water at a depth of $120 \mathrm{~m}$., 
${ }^{154}$ CPBR 9.2 objective 17.07 Development of a system of saturated exposures in the zone up to $100 \mathrm{~m}$ and the principles of the research and medical security of divers,

155 in the case of independent deep water dives, it is important to take into account the possibility of the diver ascending rapidly from considerable depths,

156 causal,

${ }^{157}$ even in peace conditions, divers need to perform the mine patrolling duty,

158 as indicated in the tactical context description,

159 cost-oriented FMEA [37],

160 here understood as ambiguous,

161 additional work of soldiers outside their duty hours is legally permissible,

162 for example: acidification of the body caused by strenuous training, presence of alcohol in the body, sleep deprivation, etc.,

163 breathing mix supplied in the rebreather,

164 Standard Operating Procedures,

165 Good Laboratory Practice,

166 impact,

167 it also seems possible to apply neon,

168 above $1 \%$ but not more than $3 \%$,

169 in real-life conditions, such verification has so far been difficult to implement,

170 prediction,

171 a natural example can be such as learning of weather processes occurring in the system atmosphere that allows to predict weather phenomena with sufficient repeatability and satisfactory precision,

172 sufficiently precise and reproducible for the intended use,

173 scientifically based predictions of pathways for future processes or changes in system characteristics,

174 Critical to Quality. 